OPEN ACCESS

Edited by:

Li Liu,

Arizona State University, United States

Reviewed by:

Prashanth N. Suravajhala, Birla Institute of Scientific Research,

India

Charles Rosser, Cedars-Sinai Medical Center, United States

*Correspondence:

Rui Batista

rbatista@ipatimup.pt

Specialty section: This article was submitted to

Genomic Assay Technology,

a section of the journal

Frontiers in Genetics

Received: 03 June 2019 Accepted: 08 November 2019 Published: 18 December 2019

Citation:

Batista R, Vinagre J, Prazeres $H$, Sampaio $C$, Peralta $P$, Conceição $P$,

Sismeiro $A$, Leão $R$, Gomes $A$,

Furriel F, Oliveira C, Torres JN, Eufrásio $P$, Azinhais $P$, Almeida $F$,

Gonzalez ER, Bidovanets $B$,

Ecke T, Stinjs P, Pascual ÁS,

Abdelmalek $R$, Villafruela $A$, Beardo-Villar P, Fidalgo N, Öztürk H,

Gonzalez-Enguita C, Monzo J,

Lopes T, Álvarez-Maestro M,

Servan PP, De La Cruz SMP, Perez MPS, Máximo $V$ and Soares $P$

(2019) Validation of a Novel, Sensitive, and Specific Urine-Based Test for Recurrence Surveillance of

Patients With Non-Muscle-

Invasive Bladder Cancer in a Comprehensive Multicenter Study.

Front. Genet. 10:1237.

doi: 10.3389/fgene.2019.01237

\section{Validation of a Novel, Sensitive, and Specific Urine-Based Test for Recurrence Surveillance of Patients With Non-Muscle-Invasive Bladder Cancer in a Comprehensive Multicenter Study}

Rui Batista ${ }^{1,2,3,4 *}$, João Vinagre ${ }^{1,2,3,5}$, Hugo Prazeres ${ }^{1,2,3,6}$, Cristina Sampaio ${ }^{1,2}$, Pedro Peralta ${ }^{7}$, Paulo Conceição ${ }^{7}$, Amílcar Sismeiro ${ }^{7}$, Ricardo Leão ${ }^{8,9}$, Andreia Gomes $^{8}$, Frederico Furriel ${ }^{9}$, Carlos Oliveira ${ }^{8}$, João Nuno Torres $^{8}$, Pedro Eufrásio ${ }^{9}$, Paulo Azinhais $^{9}$, Fábio Almeida ${ }^{10}$, Edwin Romero Gonzalez ${ }^{11}$, Bohdan Bidovanets ${ }^{12}$, Thorsten Ecke ${ }^{13}$, Pascal Stinjs ${ }^{14}$, Álvaro Serrano Pascual ${ }^{15}$, Rabehi Abdelmalek ${ }^{16}$, Ainara Villafruela ${ }^{17}$, Pastora Beardo-Villar ${ }^{18}$, Nuno Fidalgo ${ }^{19}$, Hakan Öztürk ${ }^{20}$, Carmen Gonzalez-Enguita ${ }^{21}$, Juan Monzo ${ }^{21}$, Tomé Lopes $^{22}$, Mario Álvarez-Maestro ${ }^{23}$, Patricia Parra Servan ${ }^{24}$, Santiago Moreno Perez De La Cruz ${ }^{25}$, Mario Pual Sanchez Perez ${ }^{26}$, Valdemar Máximo ${ }^{1,2,4}$ and Paula Soares ${ }^{1,2,3,5}$

${ }^{1}$ i3S - Instituto de Investigação e Inovação em Saúde, Porto, Portugal, ${ }^{2}$ Institute of Molecular Pathology and Immunology of the University of Porto (IPATIMUP), Porto, Portugal, ${ }^{3}$ U-Monitor Lda, Porto, Portugal, ${ }^{4}$ Faculty of Medicine, University of Porto, Porto, Portugal, ${ }^{5}$ Department of Pathology, Faculty of Medicine, University of Porto, Porto, Portugal, ${ }^{6}$ Department of Molecular Pathology, Portuguese Institute of Oncology, Coimbra, Portugal, ' Department of Urology Service. Portuguese Institute of Oncology, Coimbra, Portugal, ${ }^{8}$ Department of Urology, Hospital de Braga, Braga, Portugal, ${ }^{9}$ Department of Urology, Hospital CUF Coimbra, Coimbra, Portugal, ${ }^{10}$ Department of Urology, Hospital Universitário Fernando Pessoa, Porto, Portugal, ${ }^{11}$ Department of Urology, Hospital Zafra-Llerena, Badajoz, Spain, ${ }^{12}$ Department of Surgery, Ternopil Regional Oncology Center, Ternopil, Ukraine, ${ }^{13}$ Department of Urology, Helios Hospital, Bad Saarow, Germany, ${ }^{14}$ Department of Urology, St. Antonius Hospital, Nieuwegein, Netherlands, ${ }^{15}$ Servicio de Urología, Hospital Clínico San Carlos, Madrid, Spain, ${ }^{16}$ Independent Researcher, El-Eulma, Algeria, ${ }^{17}$ Department of Urology, Hospital Universitario Donostia, San Sebastian, Spain, ${ }^{18}$ Department of Urology, Hospital Universitario de Araba, Vitória, Spain, ${ }^{19}$ Department of Urology, Hospital Garcia de Horta, Lisbon, Portugal, ${ }^{20}$ Department of Urology, Medicalpark Izmir Hospital, Izmir, Turkey, ${ }^{21}$ Department of Urology, Hospital Universitario Fundacion Jiménez Díaz, Madrid, Spain, ${ }^{22}$ Department of Urology, Hospital de Santa Maria, Lisbon, Portugal, ${ }^{23}$ Department of Urology, Hospital Universitário La Paz, Madrid, Spain, ${ }^{24}$ Department of Urology, Hospital de Mérida, Badajoz, Spain, ${ }^{25}$ Department of Urology, Hospital Don BenitoVillanueva, Badajoz, Spain, ${ }^{26}$ Department of Urology, Hospital Universitário de Badajoz, Badajoz, Spain

Bladder cancer $(\mathrm{BC})$, the most frequent malignancy of the urinary system, is ranked the sixth most prevalent cancer worldwide. Of all newly diagnosed patients with BC, 70-75\% will present disease confined to the mucosa or submucosa, the non-muscle-invasive BC (NMIBC) subtype. Of those, approximately 70\% will recur after transurethral resection (TUR). Due to high rate of recurrence, patients are submitted to an intensive follow-up program maintained throughout many years, or even throughout life, resulting in an expensive follow-up, with cystoscopy being the most cost-effective procedure for NMIBC screening. Currently, the gold standard procedure for detection and follow-up of NMIBC is based on the association of cystoscopy and urine cytology. As cystoscopy is a very invasive approach, over the years, many different noninvasive assays (both based in serum and urine samples) have been developed in order to search genetic and protein alterations related to the development, progression, and recurrence of BC. TERT promoter mutations and FGFR3 
hotspot mutations are the most frequent somatic alterations in $\mathrm{BC}$ and constitute the most reliable biomarkers for $\mathrm{BC}$. Based on these, we developed an ultra-sensitive, urine-based assay called Uromonitor ${ }^{\circledR}$, capable of detecting trace amounts of TERT promoter (c.1-124C $>$ T and c.1-146C > T) and FGFR3 (p.R248C and p.S249C) hotspot mutations, in tumor cells exfoliated to urine samples. Cells present in urine were concentrated by the filtration of urine through filters where tumor cells are trapped and stored until analysis, presenting longterm stability. Detection of the alterations was achieved through a custom-made, robust, and highly sensitive multiplex competitive allele-specific discrimination PCR allowing clear interpretation of results. In this study, we validate a test for NMIBC recurrence detection, using for technical validation a total of 331 urine samples and 41 formalin-fixed paraffin-embedded tissues of the primary tumor and recurrence lesions from a large cluster of urology centers. In the clinical validation, we used 185 samples to assess sensitivity/specificity in the detection of NMIBC recurrence vs. cystoscopy/cytology and in a smaller cohort its potential as a primary diagnostic tool for NMIBC. Our results show this test to be highly sensitive (73.5\%) and specific (93.2\%) in detecting recurrence of $\mathrm{BC}$ in patients under surveillance of NMIBC.

Keywords: non-muscle invasive bladder cancer, TERT promoter mutation, FGFR3 mutation, urinary test, Uromonitor ${ }^{\circledR}$

\section{INTRODUCTION}

Bladder cancer is the most frequent malignancy involving the urinary system and affects approximately four times more males than females (Miyazaki and Nishiyama, 2017). Worldwide, bladder cancer is the sixth most diagnosed cancer in men; when considering both genders, it ranks the 10th most diagnosed and the sixth position in prevalence (Ferlay et al., 2018; Ferlay et al., 2019). Of all patients newly diagnosed with bladder cancer, around three quarters present disease confined to the mucosa or submucosa (Sanli et al., 2017), the so-called, non-muscle-invasive bladder cancer (NMIBC) subtype (Babjuk et al., 2018). The remaining are classified as muscle invasive bladder cancer (MIBC), reflecting their capacity to infiltrate the muscle layer of the bladder (Alfred Witjes et al., 2017; Sanli et al., 2017). The current treatment for NIMBC is transurethral resection (TUR); following TUR treatment, $70 \%$ of the NMIBC patients will recur after primary tumor removal and $10-20 \%$ will recur as MIBC, with the capacity to progress and develop metastatic disease (Kaufman et al., 2009; van der Heijden, 2009; Chamie et al., 2013). This high rate of recurrence requires that patients are submitted to an intensive follow-up program. Major guidelines from the European Association of Urology (EAU) and American Urological Association (AUA) recommend cystoscopy and urinary cytology that, depending from the grade, can be as often as every 3 months in the first 2 years, semi-annually during the subsequent 3 years, and annually thereafter (Kassouf et al., 2016; Alfred Witjes et al., 2017; Babjuk et al., 2018). This intensive follow-up is maintained throughout many years following the initial diagnosis and indicates bladder cancer as a type of cancer with the most expensive follow-up (Kamat et al., 2011; Yeung et al., 2014). Cystoscopy is invasive and uncomfortable for patients due to the technical requirements of the procedure; still, it renders the more accurate diagnosis method for bladder cancer
(Geavlete et al., 2012). Contrary to cystoscopy, noninvasive urine cytology is an economical approach, easier to perform, and when high-grade tumors are considered, the sensitivity is high (84\%). The major limitation of urine cytology is its overall sensitivity to detect low-grade tumors (NMIBC), where the sensitivity decreases to $16 \%$, precluding its use in the detection of those lesions (Yafi et al., 2015). The combination of all these facts leads to the opportunity for developing new, alternative, and minimally invasive methods to detect bladder cancer. As urine is in direct contact with the inner part of the bladder, cells from the epithelium, including scammed cells from bladder tumors, can exfoliate and be detected in urine and used to evaluate and monitor the presence of neoplasia in a noninvasive approach (Botezatu et al., 2000; Zwarthoff, 2008; Ralla et al., 2014; Critelli et al., 2016; Togneri et al., 2016). Over the years, many different noninvasive assays have been developed in order to search genetic and protein alterations known to be involved in the development, progression, and recurrence of bladder cancer, both in serum and urine samples, with the purpose to diagnose and monitor bladder cancer (Soloway et al., 1996; Fradet and Lockhard, 1997; Pode et al., 1999; Kruger et al., 2003; Tetu et al., 2005; Moonen et al., 2007; Halling and Kipp, 2008; Serizawa et al., 2011; Goodison et al., 2012; Kinde et al., 2012; Kinde et al., 2013; Allory et al., 2014; Bansal et al., 2014; Hurst et al., 2014; Ralla et al., 2014; Wang et al., 2014; Ellinger et al., 2015; Yafi et al., 2015; Springer et al., 2018; Miyake et al., 2018). Some of these tests presented values of sensitivity and specificity higher than urinary cytology and achieved FDA approval for bladder cancer diagnosis. Despite high sensitivities and specificities, all these molecular assays present inconvenient rates of false-positive results (Hajdinjak, 2008; Dimashkieh et al., 2013; Gopalakrishna et al., 2017; Springer et al., 2018). False-positive rates could result from several factors, including the presence of benign conditions as hematuria, cystitis, lithiasis, urinary tract infections, and 
inflammation or even because of repeated instrumentation, such as cystoscopy (Parker and Spiess, 2011; Dal Moro et al., 2013). A meta-analysis about the performance of urinary biomarkers concluded that most of the available urinary biomarkers do not detect the presence of bladder cancer in a proportion of patients and allow false-positive results in others, more frequently in lowstage and low-grade tumors (Chou et al., 2015). So, more reliable biomarkers and assays are needed for earlier detection of bladder cancer recurrence, particularly in low-grade and low-stage NMIBC. Long non-coding RNAs (lncRNAs) have emerged as potential biomarkers since aberrant expression has been reported in bladder cancer, some upregulated (lncRNA urothelial cancer associated 1 and lncRNA metastasis-associated lung adenocarcinoma transcript 1) (Wang et al., 2008; Han et al., 2013), and others downregulated such as maternally expressed 3 (MEG3) (Ying et al., 2013). Some new potential therapeutic targets were also described, such as MIR503 host gene (MIR503HG) and lncRNA MALAT-1 (Ying et al., 2012; Qiu et al., 2019). Recently, telomerase reverse transcriptase (TERT) promoter methylation aberration has been found in a large number of cancers, in a region described as TERThypermethylated oncological region (THOR). THOR hypermethylation has been found as an alternative telomerase-activating mechanism in cancer that can act independently or in conjunction with TERT promoter mutations, further supporting the utility of THOR hypermethylation as a prognostic biomarker (Lee et al., 2018). Other studies highlight that both THOR hypermethylation and TERT promoter mutations are common and coexist in bladder cancer, and while TERT promoter mutation behaves as an early event in bladder carcinogenesis, THOR hypermethylation seems associated with disease progression, with the combined genetic and epigenetic alterations of TERT bringing additional prognostic value in NMIBC (Leão et al., 2019). TERT promoter mutations per se emerged as a novel biomarker detected in up to $80 \%$ of bladder cancer, independently of stage or grade (Rachakonda et al., 2013; Allory et al., 2014; Hurst et al., 2014; Hosen et al., 2015). TERT promoter (TERTp) mutations are the most common event across stages and grades in malignant bladder tumors, strongly suggesting its participation in the two major genetic pathways of urothelial tumorigenesis (Allory et al., 2014; Hurst et al., 2014). These features point TERTp mutations as a game changer in bladder cancer and pointed them to be considered as a useful urinary biomarker for disease monitoring and early detection of recurrence, even in low-grade NMIBC, where urinary cytology usually lacks sensitivity (Allory et al., 2014; Hurst et al., 2014; Vinagre et al., 2014; Descotes et al., 2017). TERTp mutations are not present in inflammatory or urinary infections, different from previously described urinary biomarkers (Raitanen et al., 2001; Chou et al., 2015; Descotes et al., 2017). TERTp mutations assumed a novel pivotal role, even surpassing the frequency of the oncogene-activating mutations in fibroblast growth factor receptor 3 (FGFR3) gene in NMIBC (Netto, 2011; Humphrey et al., 2016), one of the most relevant drivers of urothelial transformation. Cappellen et al. reported FGFR3 mutations in bladder cancer with a frequency of $35 \%$, and subsequent studies established this frequency in approximately half of the primary bladder tumors (Cappellen et al., 1999; Sibley et al., 2001). Several studies report its presence in up to $80 \%$ regarding early-stage and low-grade tumors and as absent or a very rare event in high-grade and invasive tumors (Billerey et al., 2001; van Rhijn et al., 2003; Hernandez et al., 2006; Tomlinson et al., 2007; Pandith et al., 2013). FGFR3 assumes also an important role as a predictive biomarker due to the development of FGFR3-targeted therapies. KRAS mutations, although found in a lower percentage $(11.5 \%)$ of bladder cancers, are assuming a relevant position since the detection of KRAS mutations in conjunction with the previous alterations could improve the sensitivity of a biomarker panel (Alexander et al., 2012).

The uniqueness of TERTP mutations, mainly its location in a promoter region with a GC base pair content $>50 \%$ precluded that traditional methods using standardized conditions (conventional real-time assays or even next-generation sequencing techniques) could be used with an efficient output. With this goal in mind, we developed an ultra-sensitive assay based on real-time PCR (with a proprietary reaction chemistry and probes), a urine-based test capable of detecting trace amounts of the most common alterations in NMIBC, TERTp c.1-124C > T, c.1-146C > T, and FGFR3 p.R248C, p.S249C hotspot mutations, in urine samples.

\section{MATERIAL AND METHODS}

All procedures described in this study were in accordance with national and institutional ethical standards and the Declaration of Helsinki. Written informed consent was obtained from the patients participating in the study. Procedures were previously approved by Ethical Review Committee IPO-Coimbra (03/ $\mathrm{TI} / 15)$. Inclusion and exclusion criteria for each analysis are detailed in Supplementary Table 1.

\section{Sample Collection Urine Samples}

Urine samples from each participating urology center were collected and processed for delivery during routine urology appointments and previously to cystoscopy intervention, according to Uromonitor recommendations. Urine samples were filtered through a pretreated $0.80-\mu \mathrm{m}$ nitrocellulose syringe filter (Whatman ${ }^{\circledR}$ Filter-Z612545, Merck, Germany) containing a homemade conservative storage buffer (10 mM glutathione, $1 \mathrm{M}$ lithium chloride-6 M urea-30 mM Biuret, 2 M EDTA (E7889$100 \mathrm{ML}$ ) (information on this process is available in the video on the Supplementary-Video 1). Filters were then sent to the central lab at Ipatimup/I3S (Porto, Portugal). After arrival, filters were stored at $2-8^{\circ} \mathrm{C}$ for a maximum of 1 month until DNA extraction procedure.

\section{Tissue Samples}

Formalin-fixed paraffin-embedded (FFPE) tissues from primary tumor and/or from recurrent lesions from the cohort in study were obtained from the repository of tumors of the Instituto Português de Oncologia de Coimbra Francisco Gentil, E.P.E (IPOC-FG). Clinicopathological and follow-up data were retrieved from the files of the Department of Pathology of IPOC-FG. 


\section{Cohort's Characteristics-Urine and FFPE Cohorts}

We studied a total of 372 samples (331 urine samples and 41 FFPE) collected from 18 urology centers (Supplementary Table 2). Technical validation of the assay was done in an independent setting where we studied a total of 334 samples from urine and FFPE (presented below). Clinicopathological and follow-up data were retrieved from the files of the centers involved in this study (Supplementary Figures 1 and 2).

The main aim of our study was to validate our new molecular panel in samples obtained through noninvasive procedures. For this, we performed technical validation by analyzing a total of 331 urine samples. The clinical validation was performed by accessing the test's ability to correctly detect patients who do have the condition, by calculating the ratio between the number of the test true positives and the total number of patients that harbor active disease (sensitivity). Also, specificity, the test's ability to correctly reject healthy patients without a condition, was calculated with the ratio between the number of true negatives obtained by the test and the total number of patients that do not harbor disease at the time of the test. Positive predictive value (PPV) (ratio between test true positives and all the test positives) and negative predictive value (NPV) (ratio between test true negatives and all the test negatives) were also calculated, aiming at knowing after the test result, the probability that the patient has (or does not have) the disease. All these calculations were done using data from 185 patients.

Thus, urine samples from 185 patients (77\% males and 33\% females), with a median age of 71 years (range, 25-91) Table 1 , were used and were subdivided into independent groups (that may overlap samples) (Table 2).

FFPE tissues of the primary tumor $(n=9)$ and/or of the recurrence lesions $(n=32)$ were also analyzed to test the performance of this assay in a different biological sample (FFPE) other than urine.

\section{Cystoscopy, Cytology, and Tumor Resected Evaluation}

Cystoscopy was considered positive when an unequivocal lesion deserving surgical treatment (despite the pathology result of the resected lesion) was observed by the urologist. Urine cytology and tissue pathology were performed by each pathology department from each center. In 41 cases, the diagnosis was confirmed in the histological examination of the lesion in the TUR.

\section{DNA Extraction}

\section{Urine Samples}

Filters used for urine filtration were stabilized at room temperature for $30 \mathrm{~min}$. Upon filtration, quality DNA for further processing is obtained on filters that can be stored at $4^{\circ} \mathrm{C}$, up to 3 months (Supplementary Figure 3). In an inverted position, filters were attached to a $2-\mathrm{ml}$ microcentrifuge tube and a cell lysis solution was injected through each filter and collected in a microcentrifuge tube. Filtered lysates were incubated at $60^{\circ} \mathrm{C}$ for $30 \mathrm{~min}$ with $30 \mu \mathrm{l}$ of proteinase $\mathrm{K}$ at $10 \mathrm{mg} / \mathrm{ml}$, exposed to chaotropic lysis/binding buffer (Citogene Cell Lysis Buffer,
TABLE 1 | Clinical validation cases information and clinicopathological data.

\begin{tabular}{|c|c|c|}
\hline & Characteristics & Total cases $(n=185)$ \\
\hline \multicolumn{3}{|l|}{ Age (years) } \\
\hline & Median age (range) & $71(25-91)$ \\
\hline \multicolumn{3}{|l|}{ Age cluster, $n(\%)$} \\
\hline & 20-39 & $9(4.9)$ \\
\hline & $40-59$ & $39(21.3)$ \\
\hline & $60-79$ & $102(55.7)$ \\
\hline & $80+$ & $33(18.0)$ \\
\hline \multicolumn{3}{|l|}{ Gender, $n(\%)$} \\
\hline & Female & $41(23.2)$ \\
\hline & Male & $136(76.8)$ \\
\hline \multicolumn{3}{|l|}{ Smoking status, $n$ (\%) } \\
\hline & Yes/Former & $45(39.5)$ \\
\hline & No & $69(60.5)$ \\
\hline \multicolumn{3}{|l|}{ Disease status, $n(\%)$} \\
\hline & Primary & $122(65.9)$ \\
\hline & Recurrence & $63(34.1)$ \\
\hline \multicolumn{3}{|l|}{ Stage, $n(\%)$} \\
\hline & $\mathrm{Cis} / \mathrm{Tis}$ & $5(9.8)$ \\
\hline & $\mathrm{Ta}$ & $32(62.7)$ \\
\hline & $\mathrm{T} 1$ & $12(23.5)$ \\
\hline & $\mathrm{T} 2$ & $1(2)$ \\
\hline & Hep.Met & $1(2)$ \\
\hline \multicolumn{3}{|l|}{ Grade, $n(\%)$} \\
\hline & Low grade & $25(51)$ \\
\hline & High grade & $24(49)$ \\
\hline \multicolumn{3}{|l|}{ Urine cytology, n (\%) } \\
\hline & Positive/atypical cytology & $12(14.3)$ \\
\hline & Negative cytology & $72(85.7)$ \\
\hline \multicolumn{3}{|l|}{ Cystoscopy, $n$ (\%) } \\
\hline & Positive & $65(35.2)$ \\
\hline & Negative & $120(64.8)$ \\
\hline
\end{tabular}

TABLE 2 | Cohorts used in this study.

\begin{tabular}{|c|c|c|}
\hline Cohort name & Cohort designation & No. of samples \\
\hline Follow-up cohort & $\begin{array}{l}\text { Urine samples from patients } \\
\text { under follow-up for NMIBC }\end{array}$ & 122 \\
\hline Initial diagnosis cohort & $\begin{array}{l}\text { Urine samples from patients } \\
\text { screened for bladder cancer }\end{array}$ & 63 \\
\hline Tumor samples cohort & $\begin{array}{l}\text { FFPE samples from primary } \\
\text { tumors and recurrence from } \\
\text { patients under follow-up for } \\
\text { NMIBC }\end{array}$ & 41 \\
\hline $\begin{array}{l}\text { Uromonitor + KRAS } \\
\text { follow-up cohort }\end{array}$ & $\begin{array}{l}\text { Urine samples from } \\
\text { patients under follow-up for } \\
\text { NMIBC screened for both } \\
\text { Uromonitor }{ }^{\circledR} \text { and KRAS } \\
\text { hotspot alterations }\end{array}$ & 24 \\
\hline $\begin{array}{l}\text { Uromonitor + KRAS } \\
\text { initial diagnosis cohort }\end{array}$ & $\begin{array}{l}\text { Urine samples from patients } \\
\text { screened for bladder cancer } \\
\text { for both Uromonitor }{ }^{\circledR} \text { and } \\
\text { KRAS hotspot alterations }\end{array}$ & 25 \\
\hline
\end{tabular}

Citomed, Portugal) to release nucleic acids and protect the genomic DNA from DNases. The microcentrifuge tube content was then processed according to the manufacturer's protocol of the Norgen ${ }^{\circledR}$ Plasma/Serum Cell-Free Circulating DNA Purification Mini Kit (Norgen Biotek Corp, Canada). 


\section{Tissue Samples}

DNA from FFPE tissues was retrieved from $10-\mu \mathrm{m}$ cuts after careful manual dissection. Slides were deparaffinized in xylene $(2 \times 10 \mathrm{~min})$, followed by incubation in $100 \%$ alcohol $(2 \times 5$ $\mathrm{min})$. Tumor tissue was removed from the slides into a $1.5-\mathrm{ml}$ microcentrifuge tube. DNA extraction was performed using the Ultraprep Tissue DNA Kit (AHN Biotechnologie, Germany) according to the manufacturer's instructions. The DNA extracted was quantified by spectrophotometry using Nanodrop ND-1000, and quality was assessed by analysis of 260/280 and 260/230-nm ratios.

\section{Urine Testing Workflow}

The Uromonitor ${ }^{\circledR}$ is a custom-made full working procedure developed and optimized for the detection in a real-time PCR platform of oncogene hotspot mutations in bladder cancer tumor cells, exfoliated to urine, particularly TERTp c.1-124C > T, TERTp c.1-146C > T, FGFR3 p.R248C, and FGFR3 p.S249C alterations (Figure 1). All the tests done in this study were performed in the central lab at Ipatimup/I3S by the same lab professional, ensuring minor variability in data creation and analysis.

Mutation detection is achieved by real-time PCR amplification curve analysis. Positive and negative mutation control samples are included in each run to ensure the assay's validity. For TERTp c.1$124 \mathrm{C}>\mathrm{T}$ and c.1-146C $>\mathrm{T}$ alteration screening, we developed an improved real-time allelic discrimination assay (further referred to in the text as TERT-124 and TERT-146 assays), with the use of
Locked Nucleic Acid (LNA probes) (Figures 2A, B). LNA probes allowed modulating the melting temperature on specific bases of the probe, enhancing the possibility to achieve preferential melting temperatures in short probe sequences. LNA probes greatly improve allelic discrimination, allowing higher stability on the binding to a specific target even with a shorter sequence. When in the presence of a base pair mismatch, such specificity is lost due to a large melting temperature difference. This leads to the impossibility for the LNA probe to bind to a sequence that contains only one base pair mismatch. This high specificity to the target sequence renders this type of probe perfect for allelic discrimination experiments (Supplementary Figure 4).

For FGFR3 mutations selected for screening (p.R248C and p.S249C), we designed for each mutation a competitive allelespecific real-time detection PCR (further referred to in the text as FGFR3 248 and FGFR3 249 assays), based on the design of a mutation allele primer, a wild-type allele blocker, a locus reverse primer, and a fluorescent probe for real-time detection of the generated amplicon (Figures 2C, D). The use of a molecular blocker suppressed the amplification of the wild-type allele in order to not interfere with the amplification of the mutant allele. By this technique, we improved current detection limit for the selected alterations compared to Sanger sequencing, enhancing the ability to detect a minimal quantity of altered cells in a large pool of cells without alterations.

In this work, we also present preliminary results on the highsensitivity screening of KRAS codon 12 and codon 61 alterations achieved through the use of a custom-made mutation detection

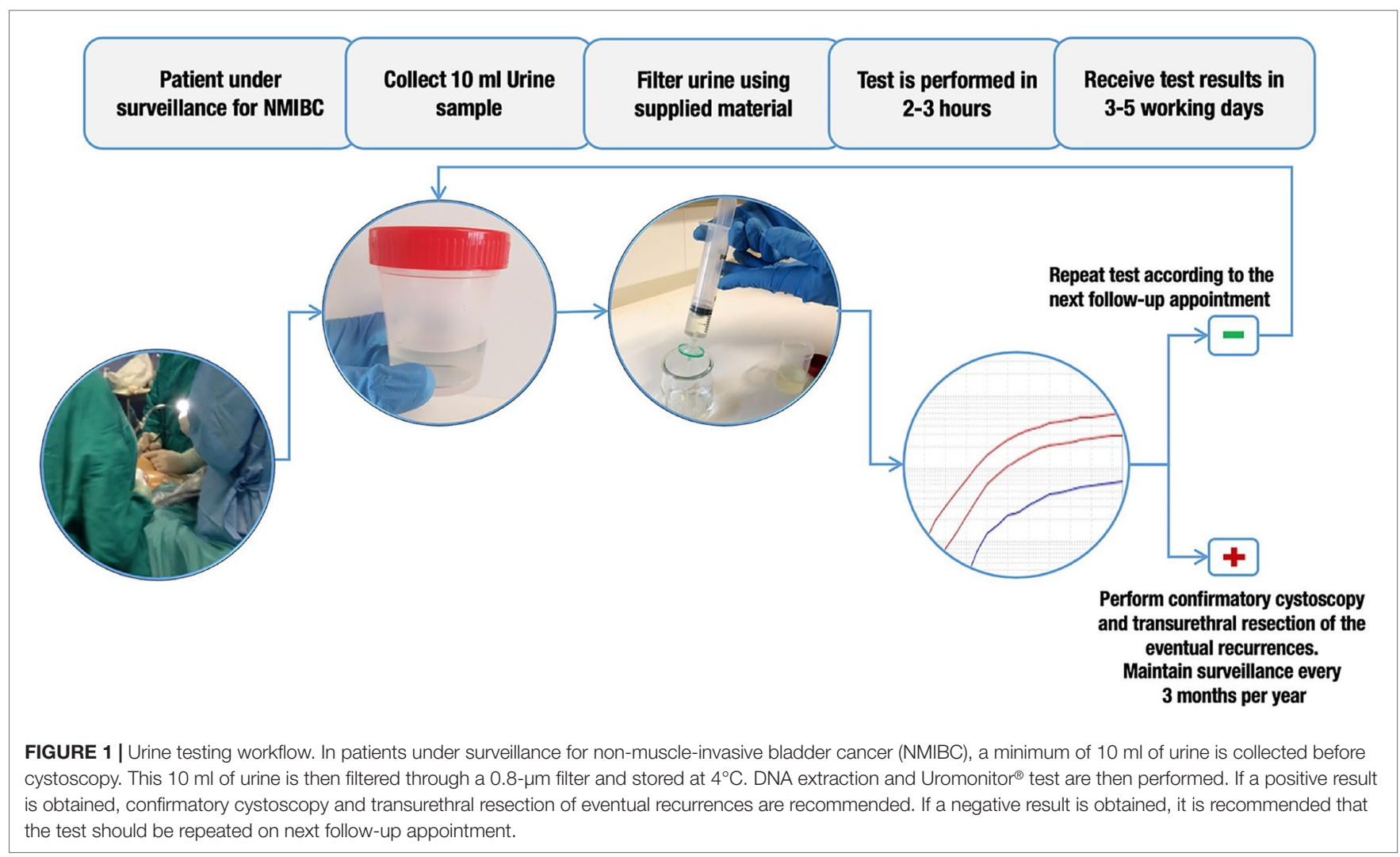


A

\section{TERTp c.1-124C>T mutation screening}
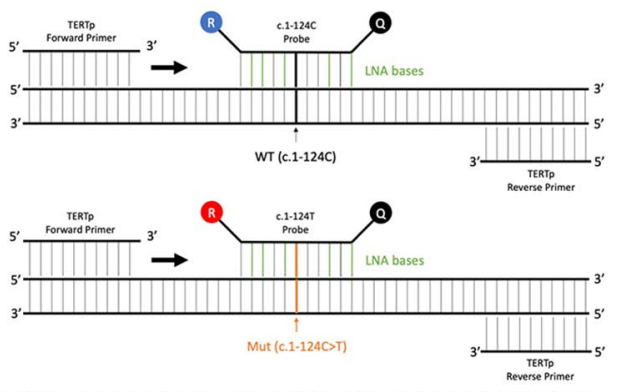

B

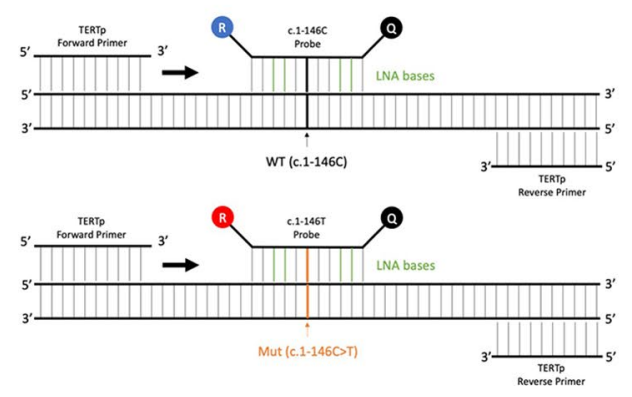

C FGFR3 c.742C $>$ G mutation screening
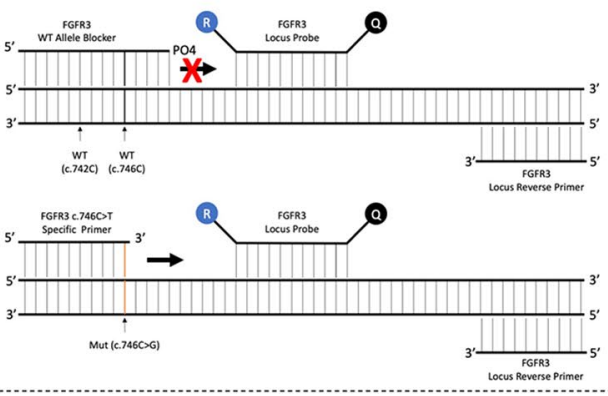

D
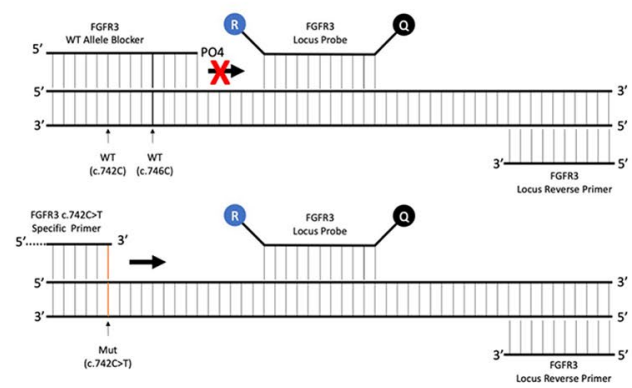

FIGURE 2 | Technical principles of the test. (A) Real-time qualitative method optimized for TERTp c.1-124C > T detection. Two competitive fluorescent probes targeting normal (WT- c.1-124C) and mutated (Mut- c.1-124C > T) alleles incorporating Locked Nucleic Acid bases are used to detect the mutations. (B) Real-time qualitative method optimized for TERTp c.1-146C > T detection. Two competitive fluorescent probes targeting normal (WT- c.1-146C) and mutated (Mut c.1-146C > T) alleles incorporating Locked Nucleic Acid bases are used to detect the mutations. (C) Real-time qualitative method optimized for FGFR3 c.742C > G detection. A mutation allele-specific primer, a phosphorylated wild-type allele blocker that completely suppresses the amplification of the wild-type allele, a locus reverse primer, and a fluorescent probe for real-time detection of the generated amplicon are used. (D) Real-time qualitative method optimized for FGFR3 c.746C > T detection. A mutation allele-specific primer, a phosphorylated wild-type allele blocker that completely suppresses the amplification of the wild-type allele, a locus reverse primer, and a fluorescent probe for real-time detection of the generated amplicon are used.

procedure developed similarly to FGFR3 hotspot mutation detection procedure, rendering this method suitable for detection of mutations in bladder cancer tumor cells exfoliated to urine.

TERT, FGFR3, and preliminary KRAS testing was performed in approximately $25 \mathrm{ng}$ of DNA extracted from cells in each filtered urine, or from $25 \mathrm{ng}$ of DNA extracted from FFPE tissues, either primary tumor and/or recurrent lesions. The extracted DNA was amplified and detected on a qPCR real-time machine using the proprietary chemistry for amplification and detection as provided in the Uromonitor ${ }^{\circledR}$ test kit for the targeted nucleotide changes in TERTP and FGFR3 genes.

\section{Uromonitor ${ }^{\circledR}$ Technical Validation}

Uromonitor $^{\circledR}$ precision was analyzed by a reproducibility test. To achieve this, 10 samples were amplified and analyzed using Uromonitor $^{\circledR}$ test (eight samples harboring mutations and two wild-type samples for the alterations of interest). These samples were amplified five times for each alteration, 1 week apart of each amplification, for 5 weeks. Uromonitor ${ }^{\circledR}$ accuracy was analyzed by two independent tests. First, it was necessary to ensure that a test containing a sample without DNA or with DNA that does not harbor any of the alterations of interest did not generate an analytical signal that may indicate a low concentration of mutation (analytical false positive). It was also necessary to assess the accuracy of the results produced by Uromonitor ${ }^{\circledR}$ test comparing it to the standard method in the detection of the alterations in study (Sanger sequencing). All the samples were validated by Sanger sequencing for the alterations in study.

\section{Uromonitor ${ }^{\circledR}$ Precision and Accuracy in Urine Samples}

To test accuracy in urine samples, 36 samples negative for all the mutations in study (status obtained by Sanger sequencing) and 36 "blank" samples (without DNA) were amplified for each alteration (false-positive testing).

Also, 252 blind tests from urine samples were analyzed (73 tests for TERTp -124 assay, 72 tests for TERTp -146 assay, 55 tests for FGFR3 248 assay, and 52 tests for FGFR3 249 assay).

\section{Uromonitor ${ }^{\circledR}$ Precision and Accuracy in FFPE Tissue Samples}

Uromonitor $^{\circledR}$ test could also be used to screen FFPE samples in patients with a history of NMIBC. To test accuracy in FFPE tissue samples, nine samples negative for all the mutations in study 
(status obtained by Sanger sequencing) and 36 "blank" samples (without DNA) were amplified for each alteration (false-positive testing). Also, 483 tests from FFPE tissue samples were analyzed (201 tests for TERTp -124 assay, 200 tests for TERTp -146 assay, 41 tests for FGFR3 248 assay, and 41 tests for FGFR3 249 assay).

\section{TERTp Detection Limit Assessment}

Uromonitor $^{\circledR}$ includes TERTp alteration detection by real-time PCR by LNA allelic discrimination probes. High GC content and thorough optimization of the amplified TERTp alterations characterize this innovative test. Since TERTp mutation detection by current methods has low sensitivity, there was the need to assess the detection limit for TERTP alterations included by the technology in the Uromonitor ${ }^{\circledR}$. To achieve this, we performed twofold serial dilutions of genomic DNA containing the studied alteration (100\% of mutated DNA) in genomic DNA wild type for the studied alterations. Serial dilutions were amplified for the corresponding detection assay. This procedure was repeated for both TERTp alterations that comprise the Uromonitor ${ }^{\circledR}$ test (Figure 3).

\section{Statistical Analysis}

Statistical analysis was performed using 21.0 SPSS Statistical Package (SPSS, Inc., 220, 2003). Descriptive statistic was done and the results are expressed as percentages and mean \pm standard deviation.

\section{A} TERTp c.1-124C>T mutation screening
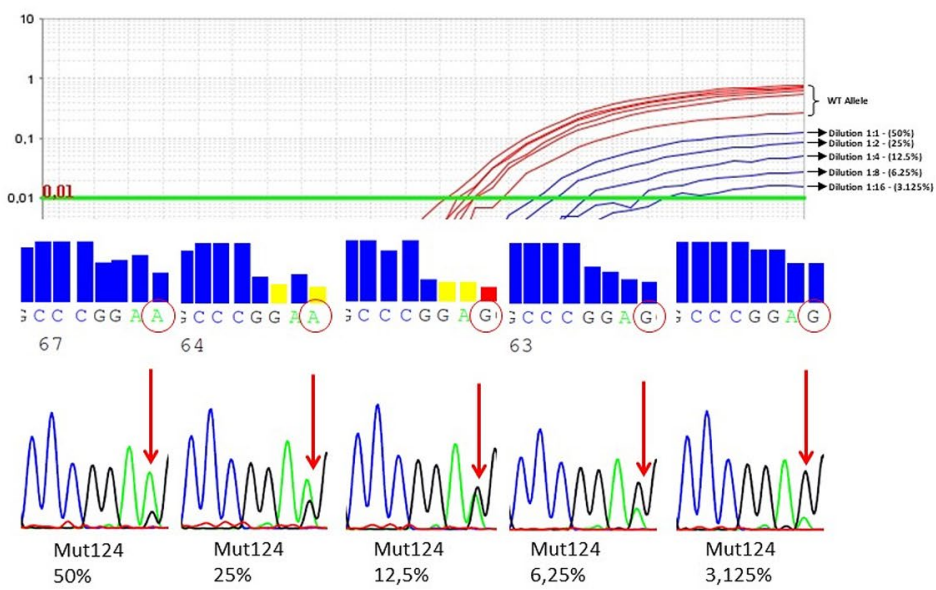

B

TERTp c.1-146C >T mutation screening
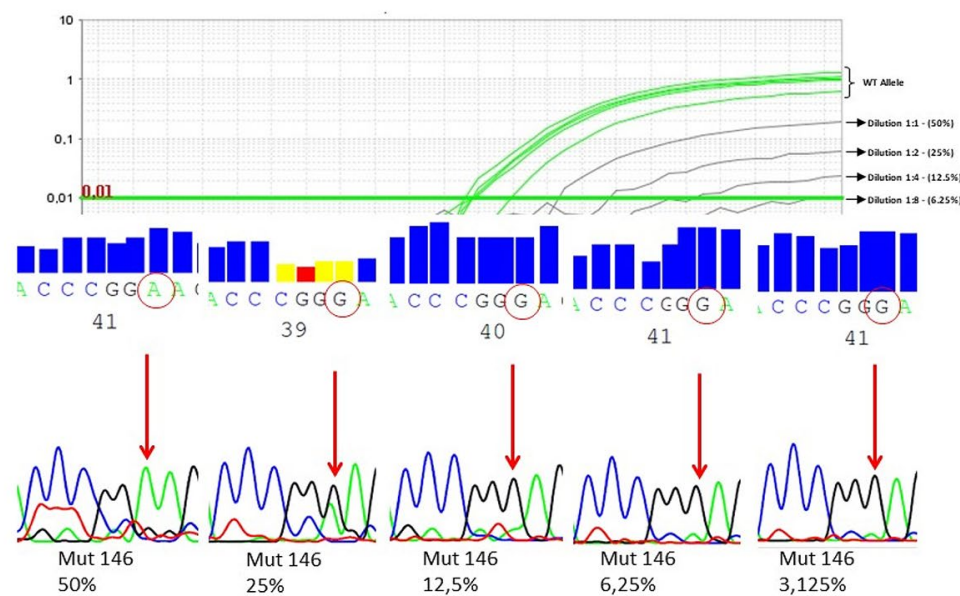

FIGURE 3 | (A) Serial dilution detection of TERTp c.1-124C > T. TERTp c.1-124C > T mutated DNA with 50\% (wild-type) WT/mutation ratio was diluted in a twofold dilution (eight dilutions) in WT DNA. Detection limit was fixed at the presence of $6.25 \%$ of TERTp c.1-124C > T alteration in the total DNA in a reaction with $25 \mathrm{ng}$ of total DNA. Below this limit, mutation detection is not guaranteed. (B) Serial dilution detection of TERTp c. $-146 \mathrm{C}>\mathrm{T}$. TERTp c.1-146C > T mutated DNA with 50\% WT/mutation ratio was diluted in a twofold dilution (eight dilutions) in WT DNA. Detection limit was fixed at the presence of $6.25 \%$ of TERTp c.1-146C > T alteration in the total DNA in a reaction with $25 \mathrm{ng}$ of total DNA. Below this limit, mutation detection is not guaranteed. 


\section{RESULTS}

\section{Genetic Alterations Technical Validation}

Uromonitor $^{\circledR}$ precision was analyzed, achieving a $100 \%$ concordance in a reproducibility test. In urine samples accuracy tests (comparisons to Sanger sequencing), TERTp -124 assay achieved 100\%, TERTp -146 assay 98.6\%, FGFR3 248 assay 87.3\%, and FGFR3 249 assay 94.2\%. Overall, Uromonitor ${ }^{\circledR}$ test presented a combined accuracy of $95.0 \%$. Uromonitor ${ }^{\circledR}$ test accuracy in FFPE tissue samples (comparison to Sanger sequencing) achieved $98.5 \%$ for TERTp -124 assay, $99.5 \%$ for TERTp -146 assay, $90.2 \%$ for FGFR3 248 assay, and $97.6 \%$ for FGFR3 249. For all assays, Uromonitor ${ }^{\circledR}$ achieved a combined 96.5\% accuracy (Supplementary Table 3). The test presented no false positives in samples without DNA (blank samples). A combined accuracy lower than $100 \%$ is justified by the detection of positivity by real-time PCR in samples for which Sanger sequencing fails to detect alteration due to lack of sensitivity.

In all the assays, the analytical detection limit was $6.25 \%$ of mutant sequences in a background of wild-type DNA. The presence of altered DNA in less than $6.25 \%$ of the total DNA in the sample may not be detected.

\section{Molecular Characterization of Urine Samples}

From the initial cohort of 331 urine samples, 304 were fully characterized for the alterations targeted by Uromonitor ${ }^{\circledR}$ test and 27 failed one or more alterations. From these, TERTp mutations were detected in $50.6 \%$ of cases $(39.0 \%$ presented the TERTP c. $1-124 \mathrm{C}>\mathrm{T}$ and $11.7 \%$ with the TERTp c.1-146C $>\mathrm{T}$ ) and FGFR3 mutations were detected in $49.4 \%$ of cases $(31.2 \%$ at codon 248 and $18.2 \%$ at codon 249 of FGFR3 protein). Further correlations with clinical data were performed for 185 samples where complete clinical data was available.

\section{Clinical Validation}

\section{Recurrence Follow-Up Cohort}

In the follow-up cohort $(n=122), 28 \%(n=34)$ of the patients recurred (confirmed by histology) of the TUR, whereas the remaining $72 \%(n=88)$ were negative for recurrence.

\section{Uromonitor $^{\circledR}$ Performance Comparison With Cytology and Cystoscopy Methods}

We analyzed and compared follow-up recurrence detection of Uromonitor ${ }^{\circledR}$ in NMIBC in comparison to routinely used screening methods such as cystoscopy and/or cytology.

Uromonitor $^{\circledR}$ sensitivity was $73.5 \%$ in the detection of TUR confirmed recurrence, with a specificity of $73.2 \%$ (Figure 4, Table 3 and Supplementary Table 4 ). The values were comparable and similar to gold-standard cystoscopy performance that in the follow-up series presented values of $79.4 \%$ and $73.2 \%$ for sensitivity and specificity, respectively (Figure 4, Table 3 and Supplementary Table 4).

Uromonitor $^{\circledR}$ sensitivity performance was much higher than cytology (42.9\% cytology sensitivity vs. $73.5 \%$ Uromonitor $^{\circledR}$ sensitivity (Figure 4, Table 3 and Supplementary Table 4).
When cytology was combined with cystoscopy, they jointly achieved an increased sensitivity of $86.7 \%$ and a slightly decreased specificity of $87.9 \%$ due to the increased rate of cytology false positives (Figure 4, Table 3 and Supplementary Table 4). Although the combination with cytology presents an upgrade to cystoscopy per se, a greater benefit is obtained when combining Uromonitor ${ }^{\circledR}$ with cystoscopy, granting together a $100 \%$ sensitivity and $88.6 \%$ specificity, clearly demonstrating an improvement in sensitivity and specificity relative to the "cystoscopy + cytology" screening method (Figure 4, Table 3 and Supplementary Table 4).

To further improve Uromonitor ${ }^{\circledR}$ test performance, we analyzed a subset of samples (Uromonitor ${ }^{\circledR}+K R A S$ follow-up cohort) for another oncogene activated in bladder cancer, KRAS hotspot alterations, and compared follow-up recurrence detection to routinely used surveillance methods.

TERT/FGFR3/KRAS increased sensitivity to $100 \%$ in the detection of TUR confirmed recurrence with a specificity of 83.3\% (Figure 4, Table 3 and Supplementary Table 4). The values were higher when compared to cystoscopy performance that in the follow-up series achieved $79.4 \%$ and $73.2 \%$ for sensitivity and specificity, respectively (Figure 4, Table 3 and Supplementary Table 4). TERT/FGFR3/KRAS sensitivity performed higher than cytology (42.9\% sensitivity and $93.9 \%$ specificity) (Figure 4, Table 3 and Supplementary Table 4).

Compared with cytology combined with cystoscopy, although this combination presents an interesting upgrade to cystoscopy per se, it does not achieve TERT/FGFR3/KRAS molecular testing performance per seor molecular testing in combination with cystoscopy screening method (Figure 4, Table 3 and Supplementary Table 4).

\section{Genetic Alterations Distribution in Recurrences and Initial Diagnostic Positive Cases}

Regarding the specific mutations detected in positive urine samples from the follow-up cohort, TERTp mutations were detected in $52.0 \%$ of cases $(44.0 \%$ presented the $-124 \mathrm{C}>\mathrm{T}$ and $8.0 \%$ with the $-146 \mathrm{C}>\mathrm{T}$ ) and FGFR3mutations were detected in $40.0 \%$ of cases $(28.0 \%$ at codon 248 and $12.0 \%$ at codon 249 of FGFR3 protein). Of the cases, $8.0 \%$ presented two concomitant alterations (two cases with TERTp c.1-124C > T and with alterations in codons 248 or 249 of FGFR3) (Figure 5).

Regarding the specific mutations detected in urine samples from the cohort of patients undergoing initial diagnosis, they were positive for Uromonitor assay as follows: TERTp mutations were detected in $35.7 \%$ of cases ( $21.4 \%$ presented the $-124 \mathrm{C}>$ $\mathrm{T}$ and $14.3 \%$ the $-146 \mathrm{C}>\mathrm{T}$ mutation) and FGFR3 mutations were detected in $28.6 \%$ of cases ( $14.3 \%$ at codon 248 and $14.3 \%$ at codon 249 of FGFR3 protein). Of the cases, 35.7\% presented TERTp and FGFR 3 concomitant alterations (one case with c.1$124 \mathrm{C}>\mathrm{T}$ and p.R248C, one case with c.1-124C $>\mathrm{T}$ and p.S249C, one case with c.1-146C > T and p.S249C, and two cases with p.R248C and p.S249C alterations (Figure 5). Nine cases in the follow-up cohort and 14 cases in the initial diagnosis cohort did not present any of the TERTP or FGFR3 screened alterations (Figure 5). 


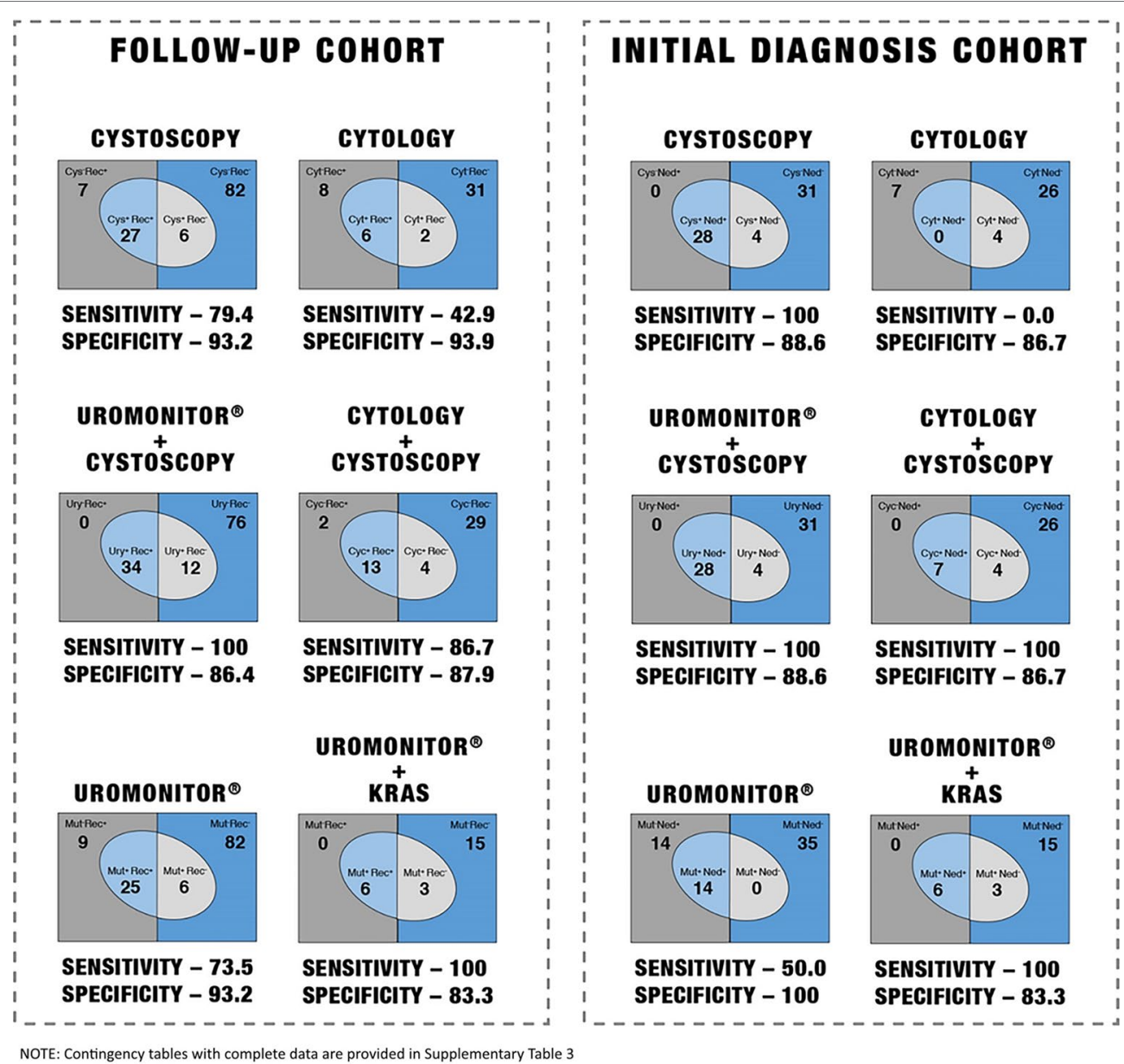

FIGURE 4 | Performance of different screening methods in non-muscle-invasive bladder cancer (NMIBC) follow-up recurrence detection and in NMIBC diagnosis.

TABLE 3 | Performance of different screening methods in non-muscle-invasive bladder cancer (NMIBC) follow-up recurrence detection and in NMIBC initial diagnosis.

\begin{tabular}{|c|c|c|c|c|c|c|}
\hline & UROMONITOR & CYSTOSCOPY & Cytology & $\begin{array}{l}\text { Cystoscopy + } \\
\text { cytology }\end{array}$ & $\begin{array}{c}\text { UROMONITOR + } \\
\text { cystoscopy }\end{array}$ & $\begin{array}{l}\text { UROMONITOR } \\
+ \text { KRAS }\end{array}$ \\
\hline \multicolumn{7}{|c|}{ Follow-up cohort } \\
\hline Specificity & 100.0 & 93.2 & 93.9 & 87.9 & 86.4 & 83.3 \\
\hline Accuracy & 77.8 & 89.3 & 78.7 & 87.5 & 90.2 & 87.5 \\
\hline PPV & 100.0 & 81.8 & 75.0 & 76.5 & 73.9 & 66.7 \\
\hline NPV & 71.4 & 92.1 & 79.5 & 93.5 & 100.0 & 100 \\
\hline Specificity & 100.0 & 88.6 & 86.7 & 86.7 & 88.6 & 80.0 \\
\hline Accuracy & 77.8 & 93.7 & 70.3 & 89.2 & 93.7 & 88.0 \\
\hline PPV & 100.0 & 87.5 & 0.0 & 63.6 & 87.5 & 87.5 \\
\hline NPV & 71.4 & 100.0 & 78.8 & 100.0 & 100.0 & 88.9 \\
\hline
\end{tabular}

Uromonitor ${ }^{\circledR}$ Performance Correlation With Stage/Grade

Tumor stage information in cases positive for recurrence was available for 26 patients. The majority of recurrencepositive cases were for stage $\mathrm{Ta}(50.0 \%)$, with $\mathrm{T} 1$ and $\mathrm{Tis}$ representing $27.0 \%$ and $19.2 \%$, respectively (Figure 6 and Supplementary Table 5). Regarding the grade, the majority of recurrence-positive tumors were high grade $(66.7 \%)$, with $33.3 \%$ being the remaining low-grade cases (Figure 7 and Supplementary Table 6). In Cis/Tis recurrence-positive patients, Uromonitor $^{\circledR}$ achieved a $100 \%$ detection rate, while in patients that recurred with a Ta tumor the detection rate was $53.8 \%$. For T1 stage positive patients, the detection rate was $71.4 \%$ (Figure 6 


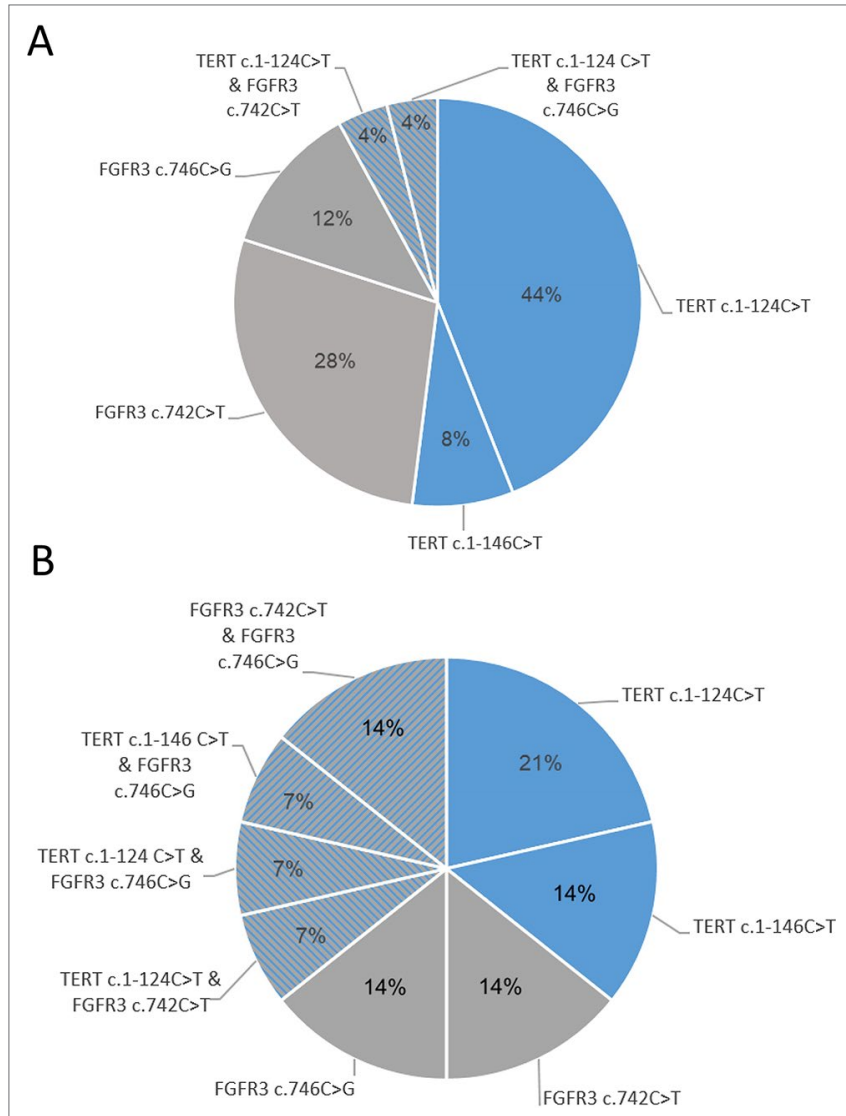

FIGURE 5 | Mutation distribution across follow-up cohort (A) and initialdiagnosis cohort (B).

and Supplementary Table 7). In low-grade recurrence-positive patients, Uromonitor ${ }^{\circledR}$ achieved a $62.5 \%$ detection rate, while in patients that recurred with a high grade, Uromonitor ${ }^{\circledR}$ tumor detection rate was $75 \%$. (Figure 7 and Supplementary Table 8). One case $(3.8 \%)$ presented a hepatic metastasis, positively detected in the urine sample by Uromonitor Uromonitor (Figure 6 and Supplementary Table 5).
Initial Diagnosis Cohort Analysis

Uromonitor $^{\circledR}$ Performance Comparison With

\section{Cystoscopy Method}

We analyzed the diagnostic performance of the test in the initial diagnosis of bladder cancer in comparison to the usual screening methods such as cystoscopy and/or cytology.

Sensitivitywas $50.0 \%$ in an initial diagnosis setting, but with a specificity of $100 \%$. These values are low in comparison with cystoscopy's virtual sensitivity of $100 \%$, although with a lower specificity of $88.6 \%$, but are much better than cytology which did not have sensitivity (0\%) and achieved $86.7 \%$ specificity.

We analyzed the performance of Uromonitor ${ }^{\circledR}+K R A S$ in the initial diagnosis of bladder cancer in comparison to cystoscopy and/or cytology. Uromonitor ${ }^{\circledR}+K R A S$ sensitivity was $93.3 \%$ in an initial diagnosis setting with a specificity of $80 \%$ (Figure 4 , Table 3, and Supplementary Table 4).

\section{DISCUSSION}

TERT promoter mutations were firstly described in sporadic and familial melanoma (Horn et al., 2013; Huang et al., 2013), and since then they were reported in several cancers, such as central nervous system (43-51\%), hepatocellular carcinoma (59\%), thyroid (follicular cell-derived tumors) (10\%), and notably in bladder cancer (59-80\%) (Killela et al., 2013; Liu et al., 2013a; Liu et al., 2013b; Nault et al., 2013; Vinagre et al., 2013; Wu et al., 2014). For bladder cancer, the TERTP mutations are independent of stage or grade (Rachakonda et al., 2013; Allory et al., 2014; Hurst et al., 2014; Hosen et al., 2015) and were reported in both non-muscle and muscle-invasive bladder cancer. As the current diagnosis and follow-up of patients with bladder cancer is highly invasive and expensive, new molecular markers are needed able to act in noninvasive approaches in order to select an optimal treatment and follow-up for each patient (Kurth et al., 1995; Pandith et al., 2013; van Kessel et al., 2013). For this purpose, we developed a novel urine-based realtime assay (Uromonitor ${ }^{\circledR}$ ), and in this study, we present the technical and clinical performance of the detection of critical

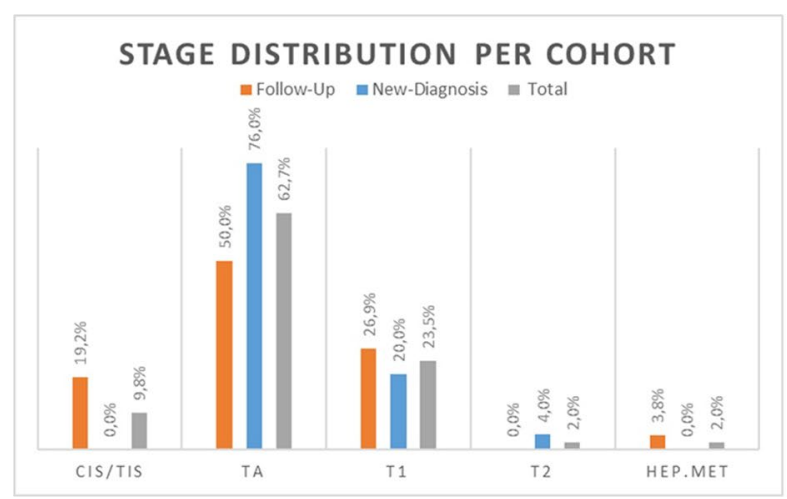

Uromonitor Performance in Recurrence detection across tumor stages

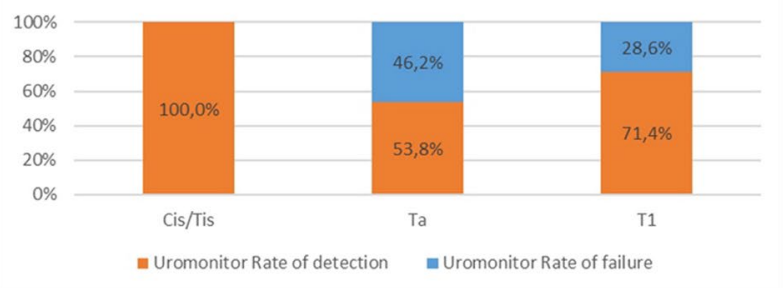

FIGURE 6 | Cohort's tumor stage distribution and Uromonitor performance in recurrence detection across tumor stages. 

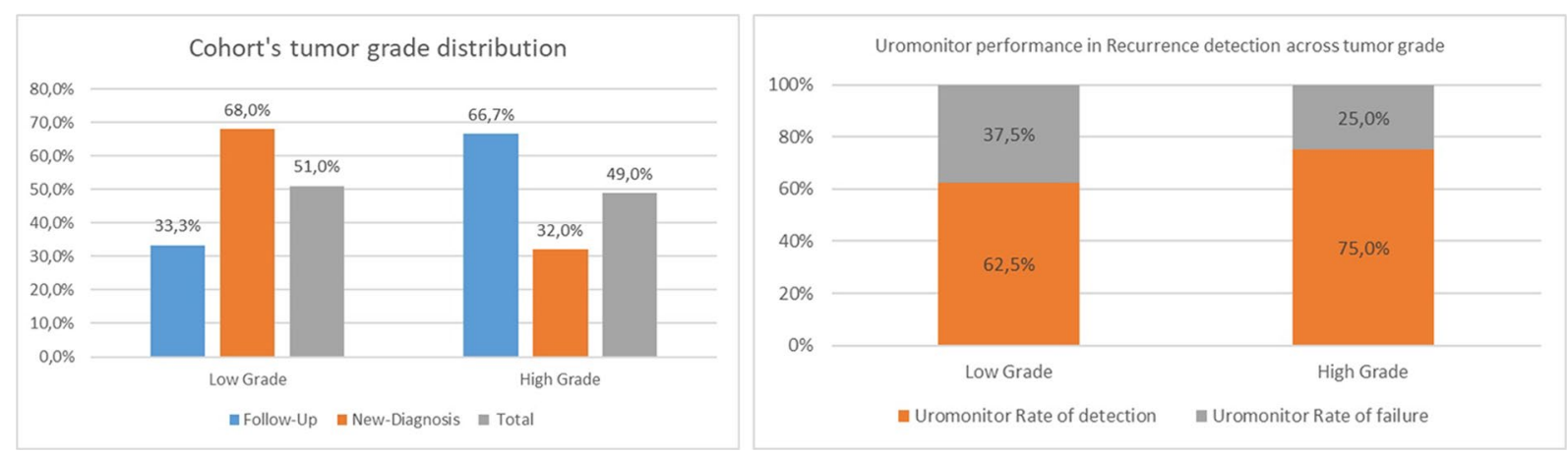

FIGURE 7 | Cohort's tumor grade and uromonitor performance in recurrence detection across tumor grades.

alterations in TERT pregion and FGFR3in DNA obtained from scammed cells of bladder present in urine. The main goal of the test is to be able to predict recurrence in NMIBC per seor in combination with cystoscopy. In this study, we analyzed and compared its performance in the follow-up of recurrence and in an initial diagnosis setting in NMIBC and in comparison with routinely used screening methods such as cystoscopy and/or cytology. The first detected limitation of this study is the recurrence rate of only $28 \%$. A value ranging $60-70 \%$ would be expected, as reported in the literature for NMINBC following TUR treatment (Antoine and van der Heijden, 2009; Kaufman et al., 2009; Chamie et al., 2013). The reason for this difference may reflect the restricted 2-year patients' follow-up considered, or patient-related factors (age, gender, multiplicity, smoking status, and adjuvant treatment) associated with recurrence frequency that are not considered at the moment (Kobayashi et al., 2014).

The sensitivity and specificity of Uromonitor ${ }^{\circledR}$ assay in the detection of TUR confirmed recurrence in the follow-up series are comparable to cystoscopy performance and in accordance with the literature that describes that about $20 \%$ of primary tumors lack TERTP and FGFR3 alterations, rendering an empirical detection rate around $80 \%$. The unsolved $20 \%$ of cases can be attributed to tumors and recurrences that may undergo different tumorigenic pathways other than the acquisition of TERTP and FGFR3 alterations that could preclude Uromonitor ${ }^{\circledR}$ testing capacity, like RASmutations (see below).

Among the recurrence-negative cases, the test was concordantly negative in $87.7 \%$ of cases. The mutational state of TERTP and FGFR3 genes in bladder cancer is considered a promising predictor of recurrence of NMIBC, demonstrated by the association between FGFR3mutation in primary tumor and later in recurrence events (Hernandez et al., 2006; Burger et al., 2008; Kompier et al., 2009; Miyake et al., 2010; Zuiverloon et al., 2010; van Rhijn et al., 2012). A specificity of $93.2 \%$ reflects the detection of three cases positive for FGFR3 mutations and three cases with TERTp mutations without evidence of recurrence by cystoscopy. These cases remained negative for recurrence during the 2-year follow-up, suggesting that they were false positives. TERTp mutations were extensively studied and are described in the literature as absent in normal tissue. Since a clear positive signal was obtained in the aforementioned cases, we cannot rule out the hypothesis that Uromonitor ${ }^{\circledR}$ high sensitivity may be detecting microscopic lesions and that may predict the appearance of a macroscopic lesion in a longer-term period beyond the 2-year follow-up.

More than half of the cases presented at least one mutational event, and it is reported that TERTp and FGFR3 mutations tend to occur more frequently together than per chance; the combination of both constitutes a more reliable biomarker for NMIBC recurrence monitoring (Hosen et al., 2015; Critelli et al., 2016).

Uromonitor $^{\circledR}$ sensitivity performance was higher than cytology, and if used as an adjunct to cystoscopy it allowed achieving a $100 \%$ sensitivity and $88.6 \%$ specificity, an important upgrade in sensitivity and specificity in comparison to the cystoscopy and cytology combination. This data demonstrates that this test, used together with cystoscopy at a routine level, will lead to a cost-effectiveness increment. It can also be used per se without any decrease in performance relative to the current routinely used methods, such as cystoscopy or if cystoscopy is not routinely available.

Uromonitor $^{\circledR}$ showed overall good performance in recurrence detection across all stages. In Cis/Tis tumors, which represent $20 \%$ of follow-up positive cases, a peak performance was obtained with a $100 \%$ detection rate. For the majority of these Cis/Tis cases TERTp alterations were present (four out of five cases, 80.0\%). Several authors reported that TERTp alterations are not associated with stage and FGFR3 hotspot alterations are rare in Cis/Tis tumors; this is concordant with our findings where only one patient presented a FGFR3 mutation.

This series was enriched with high-grade tumors, which is in contrast to the majority of the reported series of NMIBC. This might have created a bias in the results and impacted the assay performance. Development of this test is actively based in TERTP/FGFR3 alterations detection that together are more frequent in low-grade tumors; additionally, FGFR3 mutations are rare in high-grade tumors.

We also prospectively analyzed and compared initial diagnosis performance in comparison to routinely used screening methods. In an initial diagnosis setting, sensitivity was lower in 
the detection of disease compared to standard cystoscopy that is considered to virtually hold a $100 \%$ sensitivity (a value due to the absence of confirmation of tumor existence on cystoscopy negative cases) and $88.6 \%$ specificity. Among the negative cases, the Uromonitor ${ }^{\circledR}$ test was concordant in $100 \%$ of cases being highly specific. In comparison with another routine assay, Uromonitor $^{\circledR}$ largely surpasses cytology's sensitivity that could not detect any new bladder cancer-positive case ( $0 \%$ sensitivity).

Nevertheless, taking into consideration that Uromonitor ${ }^{\circledR}$ main performance was initially aimed for low-grade tumors, these series gave us the opportunity to improve Uromonitor ${ }^{\circledR}$ performance in a high-grade tumor-enriched setting. To this purpose, we included new biomarkers in the test in order to improve Uromonitor ${ }^{\circledR}$ detection rate and testing capabilities overall; we want to achieve and maintain the high sensitivity and specificity that our test offers. This led to the KRAS hotspot alterations inclusion, and this preliminary data demonstrated that, both for follow-up or initial diagnosis cases, Uromonitor ${ }^{\circledR}+$ KRAS improves significantly, reachin a $100 \%$ sensitivity in follow-up detection and $93.3 \%$ in initial-diagnosis detection and with an overall performance of $95.2 \%$ regardless of grade. With the inclusion of KRAS hotspot mutation screening together with Uromonitor $^{\circledR}$, this preliminary data presents this noninvasive approach as a true alternative to cystoscopy for NMIBC follow-up or even as a population screening and/or initial diagnosis for bladder cancer. It is also noteworthy to mention that the inclusion of FGFR3 in Uromonitor ${ }^{\circledR}$ test raises its usefulness as a biomarker test for targeted therapy.

During the course of this study, an interesting case demonstrated the capacities of these novel tests in providing new information regarding disease progression. In a patient apparently free of local disease, a TERTp mutation was detected in the urine. Although the patient did not present bladder cancer at the time, it had a hepatic metastasis. Further analysis confirmed that the hepatic metastasis presented a TERTp mutation. It will be worthwhile to investigate the usefulness of this test technology in the screening of other tumors and metastasis, namely, those harboring TERTp mutations, in urine samples.

In terms of the Uromonitor ${ }^{\circledR}$ performance in comparison with other available options, it presented improved features. Reviewed by Sapre et al. (2014), the sensitivity of other available options ranges from $50.0 \%$ to $96.6 \%$, and the tests are based on different methodology approaches, some more technically challenging and maintaining invasive requirements for the procedure. Avoidance of invasive procedures for the patients was a concern in the development of this test since morbidity of cystoscopy is often underestimated and can impact on patient adherence, with surveillance rates as low as $40 \%$ (Schrag et al., 2003). The fact that the test is conducted in urine renders it safer for patient use and with better acceptance in comparison with conventional cystoscopy. Another important aspect in the development of Uromonitor $^{\circledR}$ was the implementation ability across different centers or laboratories. For this, we concentrated on three pillars: ease of use, cost, and response time. Being a real-time PCR-based method, a technique that is already well implemented in most laboratories, not requiring a specialized technician to execute the test or dedicated apparatus, with affordable equipment and reduced costs, and, most determinately, with the capacity to output a result in $6 \mathrm{~h}$. If we compare this approach with other established next-generation sequencing (NGS)-based methods, it is promptly detected that such a fast response is not possible as it is required to have a sample and library preparation, failing the short-time frame response, the costs would increase with run and equipment requirements and NGS equipment is not widely available. Also, if we compare this to current detection methods for TERTp and/or FGFR3 based on Sanger sequencing, the high increase in sensitivity is a key factor, especially since we are trying to detect trace amount of tumor cells in urine samples.

Overall, this study demonstrates that Uromonitor ${ }^{\circledR}$ represents a highly sensitive and specific urine test in detecting recurrence of NMIBC. Taking into account the obtained results, we can view Uromonitor $^{\circledR}$, with and without KRAS mutation screening, on different levels depending on the specific needs of the patient/ healthcare professional. Uromonitor ${ }^{\circledR}$ TERTp/FGFR3 screening could be easily used in direct substitution of cytology since it presents an undoubtfully higher overall sensitivity while maintaining analysis response time and costs at an equivalent level. On the other hand, Uromonitor ${ }^{\circledR}$ TERT/FGFR3/KRAS screening, based on our preliminary results, could directly substitute cystoscopy in a specific context, such as the impossibility of performing an cystoscopy, patients refusing to perform cystoscopy, or even alternating with cystoscopy in the follow-up program in patients with low-risk, low-grade lesions, alleviating the number of cystoscopy procedures that patients are required to undergo. The rate of Uromonitor ${ }^{\circledR}$ false positives was similar to the rate of cystoscopy false positives. Our results prompt us to validate these findings in an enlarged robust independent series, in an ongoing study with a design that includes a group of benign conditions (renal lithiasis, urinary infections, hyperplasia of the prostate, and others). We intend to further test it and externally validate it to assess its cost-effectiveness and to determine its value in patients' follow-up.

\section{DATA AVAILABILITY STATEMENT}

The raw data supporting the conclusions of this article will be made available by the authors, without undue reservation, to any qualified researcher.

\section{ETHICS STATEMENT}

The studies involving human participants were reviewed and approved by Comissão de Ética do Instituto Português de Oncologia de Coimbra. The patients/participants provided their written informed consent to participate in this study.

\section{AUTHOR CONTRIBUTIONS}

RB performed all studies and wrote the draft of the manuscript. HP participated in the genetic analysis. JV, HP, VM, and PSo supervised the entire project and gave critical comments on the manuscript. CS participated in the genetic analysis, in the experimental design and 
managed the literature searches. PP, PC, AS, RL, AG, FF, CO, JT, PE, PA, FA, EG, BB, TE, PSt, AP, RA, AV, PB-V, NF, HÖ, CG-E, JM, TL, MA-M, PPS, SC, MP contributed to the sample and data collection for the study. All authors read and approved the final manuscript.

\section{FUNDING}

This study was supported by FCT ("Portuguese Foundation for Science and Technology") through a $\mathrm{PhD}$ grant to RB (SFRH/ $\mathrm{BD} / 111321 / 2015)$. Further funding was obtained from the project "Advancing cancer research: from basic knowledge to application" NORTE-01-0145-FEDER-000029: "Projetos Estruturados de I \& D \& I," funded by Norte 2020-Programa Operacional Regional do Norte. This article is a result of the project PTDC/MED-ONC/31438/2017 (The Other Faces of Telomerase: Looking beyond Tumor Immortalization), supported by Norte Portugal Regional Operational Programme (NORTE 2020), under the PORTUGAL 2020 Partnership Agreement, through the European Regional Development Fund (ERDF), COMPETE 2020-Operacional Programme

\section{REFERENCES}

Alexander, R. E., Lopez-Beltran, A., Montironi, R., MacLennan, G. T., Chen, G. R., Post, K. M., et al. (2012). KRAS mutation is present in a small subset of primary urinary bladder adenocarcinomas. Lab. Invest. 92, 188a-188a. doi: 10.1111/j.1365-2559.2012.04309.x

Alfred Witjes, J., Lebret, T., Comperat, E. M., Cowan, N. C., De Santis, M., Bruins, H. M., et al. (2017). Updated 2016 EAU guidelines on muscle-invasive and metastatic bladder cancer. Eur. Urol. 71 (3), 462-475. doi: 10.1016/j. eururo.2016.06.020

Allory, Y., Beukers, W., Sagrera, A., Flandez, M., Marques, M., Marquez, M., et al. (2014). Telomerase reverse transcriptase promoter mutations in bladder cancer: high frequency across stages, detection in urine, and lack of association with outcome. Eur. Urol. 65 (2), 360-366. doi: 10.1016/j. eururo.2013.08.052

Babjuk, M., Burger, M., Compérat, E., Gontero, P., Mostafid, A. H., Palou, J., et al. (2018). EUA Guidelines on Non-muscle-invasive Bladder Cancer. Edn. presented at the EAU Annual Congress Copenhagen 2018.

Bansal, N., Gupta, A., Sankhwar, S. N., and Mahdi, A. A. (2014). Low- and highgrade bladder cancer appraisal via serum-based proteomics approach. Clin. Chim. Acta 436, 97-103. doi: 10.1016/j.cca.2014.05.012

Billerey, C., Chopin, D., Aubriot-Lorton, M. H., Ricol, D., Gil Diez de Medina, S., Van Rhijn, B., et al. (2001). Frequent FGFR3 mutations in papillary noninvasive bladder (pTa) tumors. Am. J. Pathol. 158 (6), 1955-1959. doi: 10.1016/ S0002-9440(10)64665-2

Botezatu, I., Serdyuk, O., Potapova, G., Shelepov, V., Alechina, R., Molyaka, Y., et al. (2000). Genetic analysis of DNA excreted in urine: a new approach for detecting specific genomic DNA sequences from cells dying in an organism. Clin. Chem. 46 (8 Pt 1), 1078-1084.

Burger, M., van der Aa, M. N., van Oers, J. M., Brinkmann, A., van der Kwast, T. H., Steyerberg, E. C., et al. (2008). Prediction of progression of non-muscleinvasive bladder cancer by WHO 1973 and 2004 grading and by FGFR3 mutation status: a prospective study. Eur. Urol. 54 (4), 835-843. doi: 10.1016/j. eururo.2007.12.026

Cappellen, D., De Oliveira, C., Ricol, D., de Medina, S., Bourdin, J., SastreGarau, X., et al. (1999). Frequent activating mutations of FGFR3 in human bladder and cervix carcinomas. Nat. Genet. 23 (1), 18-20. doi: 10.1038/12615

Chamie, K., Litwin, M. S., Bassett, J. C., Daskivich, T. J., Lai, J., Hanley, J. M., et al. (2013). Recurrence of high-risk bladder cancer: a population-based analysis. VCancer 119 (17), 3219-3227. doi: 10.1002/cncr.28147 for Competitiveness and Internationalisation (POCI) and by Portuguese funds through FCT. Further funding by the European Regional Development Fund (ERDF) through the Operational Programme for Competitiveness and InternationalisationCOMPETE 2020, and Portuguese national funds via FCT, under project POCI-01-0145-FEDER-016390:CANCEL STEM.

\section{ACKNOWLEDGMENTS}

We are grateful for the Cancer Signalling and Metabolism Group for the indirect participation in this study, especially to Marcelo Correia for the manutention of immortalized cell lines important to this study.

\section{SUPPLEMENTARY MATERIAL}

The Supplementary Material for this article can be found online at: https://www.frontiersin.org/articles/10.3389/fgene.2019.01237/ full\#supplementary-material.

Chou, R., Gore, J. L., Buckley, D., Fu, R., Gustafson, K., Griffin, J. C., et al (2015). Urinary biomarkers for diagnosis of bladder cancer: a systematic review and meta-analysis. Ann. Intern. Med. 163 (12), 922-931. doi: 10.7326/M15-0997

Critelli, R., Fasanelli, F., Oderda, M., Polidoro, S., Assumma, M. B., Viberti, C., et al. (2016). Detection of multiple mutations in urinary exfoliated cells from male bladder cancer patients at diagnosis and during follow-up. Oncotarget 7 (41), 67435-67448. doi: 10.18632/oncotarget.11883

Dal Moro, F., Valotto, C., Guttilla, A., and Zattoni, F. (2013). Urinary markers in the everyday diagnosis of bladder cancer. Urologia 80 (4), 265-275. doi: 10.5301/urologia.5000041

Descotes, F., Kara, N., Decaussin-Petrucci, M., Piaton, E., Geiguer, F., RodriguezLafrasse, C., et al. (2017). Non-invasive prediction of recurrence in bladder cancer by detecting somatic TERT promoter mutations in urine. Br. J. Cancer 117 (4), 583-587. doi: 10.1038/bjc.2017.210

Dimashkieh, H., Wolff, D. J., Smith, T. M., Houser, P. M., Nietert, P. J., and Yang, J. (2013). Evaluation of urovysion and cytology for bladder cancer detection: a study of 1835 paired urine samples with clinical and histologic correlation. Cancer Cytopathol. 121 (10), 591-597. doi: 10.1002/cncy.21327

Ellinger, J., Muller, S. C., and Dietrich, D. (2015). Epigenetic biomarkers in the blood of patients with urological malignancies. Expert Rev. Mol. Diagn. 15 (4), 505-516. doi: 10.1586/14737159.2015.1019477

Ferlay, J., Ervik, M., Lam, F., Colombet, M., Mery, L., Piñeros, M., et al. (2018). Global Cancer Observatory: Cancer Today (Lyon, France: International Agency for Research on Cancer). Available from: https://gco.iarc.fr/today, accessed [29 July 2019].

Ferlay, J., Colombet, M., Soerjomataram, I., Mathers, C., Parkin, D. M., Piñeros, M., et al. (2019). Estimating the global cancer incidence and mortality in 2018: GLOBOCAN sources and methods. Int. J. Cancer 144 (8), 1941-1953. doi: 10.1002/ijc.31937

Fradet, Y., and Lockhard, C. (1997). Performance characteristics of a new monoclonal antibody test for bladder cancer: immunocyt trade mark. Can. J. Urol. 4 (3), 400-405.

Geavlete, B., Jecu, M., Multescu, R., and Geavlete, P. (2012). Narrow-band imaging cystoscopy in non-muscle-invasive bladder cancer: a prospective comparison to the standard approach. Ther. Adv. Urol. 4 (5), 211-217. doi: $10.1177 / 1756287212454181$

Goodison, S., Chang, M., Dai, Y., Urquidi, V., and Rosser, C. J. (2012). A multianalyte assay for the non-invasive detection of bladder cancer. PloS One 7 (10), e47469. doi: 10.1371/journal.pone.0047469 
Gopalakrishna, A., Fantony, J. J., Longo, T. A., Owusu, R., Foo, W. C., Dash, R., et al. (2017). Anticipatory positive urine tests for bladder cancer. Ann. Surg. Oncol. 24 (6), 1747-1753. doi: 10.1245/s10434-016-5763-5

Hajdinjak, T. (2008). UroVysion FISH test for detecting urothelial cancers: metaanalysis of diagnostic accuracy and comparison with urinary cytology testing. Urol. Oncol. 26 (6), 646-651. doi: 10.1016/j.urolonc.2007.06.002

Halling, K. C., and Kipp, B. R. (2008). Bladder cancer detection using FISH (UroVysion assay). Adv. Anat. Pathol. 15 (5), 279-286. doi: 10.1097/ PAP.0b013e3181832320

Han, Y., Liu, Y., Nie, L., Gui, Y., and Cai, Z. (2013). Inducing cell proliferation inhibition, apoptosis, and motility reduction by silencing long noncoding ribonucleic acid metastasis-associated lung adenocarcinoma transcript 1 in urothelial carcinoma of the bladder. Urology 81 (1), 209-2e1. doi: 10.1016/j. urology.2012.08.044

Hernandez, S., Lopez-Knowles, E., Lloreta, J., Kogevinas, M., Amoros, A., Tardon, A., et al. (2006). Prospective study of FGFR3 mutations as a prognostic factor in nonmuscle invasive urothelial bladder carcinomas. J. Clin. Oncol. 24 (22), 3664-3671. doi: 10.1200/JCO.2005.05.1771

Horn, S., Figl, A., Rachakonda, P. S., Fischer, C., Sucker, A., Gast, A., et al. (2013). TERT promoter mutations in familial and sporadic melanoma. Science 339 (6122), 959-961. doi: 10.1126/science.1230062

Hosen, I., Rachakonda, P. S., Heidenreich, B., de Verdier, P. J., Ryk, C., Steineck, G., et al. (2015). Mutations in TERT promoter and FGFR3 and telomere length in bladder cancer. Int. J. Cancer 137 (7), 1621-1629. doi: 10.1002/ijc.29526

Huang, F. W., Hodis, E., Xu, M. J., Kryukov, G. V., Chin, L., and Garraway, L. A. (2013). Highly recurrent TERT promoter mutations in human melanoma. Science 339 (6122), 957-959. doi: 10.1126/science.1229259

Humphrey, P. A., Moch, H., Cubilla, A. L., Ulbright, T. M., and Reuter, V. E. (2016). The 2016 WHO Classification of tumours of the urinary system and male genital organs-Part B: prostate and bladder tumours. Eur. Urol. 70 (1), 106-119. doi: 10.1016/j.eururo.2016.02.028

Hurst, C. D., Platt, F. M., and Knowles, M. A. (2014). Comprehensive mutation analysis of the TERT promoter in bladder cancer and detection of mutations in voided urine. Eur. Urol. 65 (2), 367-369. doi: 10.1016/j. eururo.2013.08.057

Kamat, A. M., Karam, J. A., Grossman, H. B., Kader, A. K., Munsell, M., and Dinney, C. P. (2011). Prospective trial to identify optimal bladder cancer surveillance protocol: reducing costs while maximizing sensitivity. BJU Int. 108 (7), 1119-1123. doi: 10.1111/j.1464-410X.2010.10026.x

Kassouf, W., Traboulsi, S. L., Schmitz-Drager, B., Palou, J., Witjes, J. A., van Rhijn, B. W., et al. (2016). Follow-up in non-muscle-invasive bladder cancerinternational bladder cancer network recommendations. Urol. Oncol. 34 (10), 460-468. doi: 10.1016/j.urolonc.2016.05.028

Kaufman, D. S., Shipley, W. U., and Feldman, A. S. (2009). Bladder cancer. Lancet 374 (9685), 239-249. doi: 10.1016/S0140-6736(09)60491-8

Killela, P. J., Reitman, Z. J., Jiao, Y., Bettegowda, C., Agrawal, N., Diaz, L. A.Jr., et al. (2013). TERT promoter mutations occur frequently in gliomas and a subset of tumors derived from cells with low rates of self-renewal. Proc. Natl. Acad. Sci. U.S.A. 110 (15), 6021-6026. doi: 10.1073/pnas. 1303607110

Kinde, I., Papadopoulos, N., Kinzler, K. W., and Vogelstein, B. (2012). FAST-SeqS: a simple and efficient method for the detection of aneuploidy by massively parallel sequencing. PloS One 7 (7), e41162. doi: 10.1371/journal.pone.0041162

Kinde, I., Munari, E., Faraj, S. F., Hruban, R. H., Schoenberg, M., Bivalacqua, T., et al. (2013). TERT promoter mutations occur early in urothelial neoplasia and are biomarkers of early disease and disease recurrence in urine. Cancer Res. 73 (24), 7162-7167. doi: 10.1158/0008-5472.CAN-13-2498

Kobayashi, H., Kikuchi, E., Mikami, S., Maeda, T., Tanaka, N., Miyajima, A., et al. (2014). Long term follow-up in patients with initially diagnosed low grade Ta non-muscle invasive bladder tumors: tumor recurrence and worsening progression. BMC Urol. 14 (1), 5. doi: 10.1186/1471-2490-14-5

Kompier, L. C., van der Aa, M. N., Lurkin, I., Vermeij, M., Kirkels, W. J., Bangma, C. H., et al. (2009). The development of multiple bladder tumour recurrences in relation to the FGFR3 mutation status of the primary tumour. J. Pathol. 218 (1), 104-112. doi: 10.1002/path.2507

Kruger, S., Mess, F., Bohle, A., and Feller, A. C. (2003). Numerical aberrations of chromosome 17 and the 9p21 locus are independent predictors of tumor recurrence in non-invasive transitional cell carcinoma of the urinary bladder. Int. J. Oncol. 23 (1), 41-48. doi: 10.3892/ijo.23.1.41
Kurth, K. H., Denis, L., Bouffioux, C., Sylvester, R., Debruyne, F. M., PavoneMacaluso, M., et al. (1995). Factors affecting recurrence and progression in superficial bladder tumors. Eur. J. Cancer 31A (11), 1840-1846. doi: 10.1016/0959-8049(95)00287-S

Leão, R., Lee, D., Figueiredo, A., Hermanns, T., Wild, P., Komosa, M., et al. (2019). Combined genetic and epigenetic alterations of the TERT promoter affect clinical and biological behavior of bladder cancer. Int. J. Cancer 144 (7), 16761684. doi: 10.1002/ijc.31935

Lee, D. D., Leão, R., Komosa, M., Gallo, M., Zhang, C. H., Lipman, T., et al. (2018). DNA hypermethylation within TERT promoter upregulates TERT expression in cancer. J. Clin. Invest. 129 (1). doi: 10.1172/JCI121303

Liu, X., Bishop, J., Shan, Y., Pai, S., Liu, D., Murugan, A. K., et al. (2013a). Highly prevalent TERT promoter mutations in aggressive thyroid cancers. Endocr. Relat. Cancer 20 (4), 603-610. doi: 10.1530/ERC-13-0210

Liu, X., Wu, G., Shan, Y., Hartmann, C., von Deimling, A., and Xing, M. (2013b). Highly prevalent TERT promoter mutations in bladder cancer and glioblastoma. Cell Cycle 12 (10), 1637-1638. doi: 10.4161/cc.24662

Miyake, M., Sugano, K., Sugino, H., Imai, K., Matsumoto, E., Maeda, K., et al. (2010). Fibroblast growth factor receptor 3 mutation in voided urine is a useful diagnostic marker and significant indicator of tumor recurrence in non-muscle invasive bladder cancer. Cancer Sci. 101 (1), 250-258. doi: 10.1111/j.1349-7006.2009.01334.x

Miyake, M., Owari, T., Hori, S., Nakai, Y., and Fujimoto, K. (2018). Emerging biomarkers for the diagnosis and monitoring of urothelial carcinoma. Res. Rep. In Urol. 10, 251. doi: 10.2147/RRU.S173027

Miyazaki, J., and Nishiyama, H. (2017). Epidemiology of urothelial carcinoma. Int. J. Urol. 24 (10), 730-734. doi: 10.1111/iju.13376

Moonen, P. M., Merkx, G. F., Peelen, P., Karthaus, H. F., Smeets, D. F., and Witjes, J. A. (2007). UroVysion compared with cytology and quantitative cytology in the surveillance of non-muscle-invasive bladder cancer. Eur. Urol. 51 (5), 12751280. doi: 10.1016/j.eururo.2006.10.044

Nault, J. C., Mallet, M., Pilati, C., Calderaro, J., Bioulac-Sage, P., Laurent, C., et al. (2013). High frequency of telomerase reverse-transcriptase promoter somatic mutations in hepatocellular carcinoma and preneoplastic lesions. Nat. Commun. 4, 2218. doi: $10.1038 /$ ncomms 3218

Netto, G. J. (2011). Molecular biomarkers in urothelial carcinoma of the bladder: are we there yet? Nat. Rev. Urol. 9 (1), 41-51. doi: 10.1038/nrurol.2011.193

Pandith, A. A., Shah, Z. A., and Siddiqi, M. A. (2013). Oncogenic role of fibroblast growth factor receptor 3 in tumorigenesis of urinary bladder cancer. Urol. Oncol. 31 (4), 398-406. doi: 10.1016/j.urolonc.2010.07.014

Parker, J., and Spiess, P. E. (2011). Current and emerging bladder cancer urinary biomarkers. ScientificWorldJournal 11, 1103-1112. doi: 10.1100/tsw.2011.104

Pode, D., Shapiro, A., Wald, M., Nativ, O., Laufer, M., and Kaver, I. (1999). Noninvasive detection of bladder cancer with the BTA stat test. J. Urol. 161 (2), 443-446. doi: 10.1016/S0022-5347(01)61918-9

Qiu, F., Zhang, M. R., Zhou, Z., Pu, J. X., and Zhao, X. J. (2019). IncRNA MIR503HG functioned as a tumor suppressor and inhibited cell proliferation, metastasis and epithelial-mesenchymal transition in bladder cancer. J. Cell. Biochem. 120 (6), 10821-10829. doi: 10.1002/jcb.28373

Rachakonda, P. S., Hosen, I., de Verdier, P. J., Fallah, M., Heidenreich, B., Ryk, C., et al. (2013). TERT promoter mutations in bladder cancer affect patient survival and disease recurrence through modification by a common polymorphism. Proc. Natl. Acad. Sci. U.S.A. 110 (43), 17426-17431. doi: 10.1073/pnas. 1310522110

Raitanen, M. P., Kaasinen, E., Lukkarinen, O., Kauppinen, R., Viitanen, J., Liukkonen, T., et al. (2001). Analysis of false-positive BTA STAT test results in patients followed up for bladder cancer. Urology 57 (4), 680-684. doi: 10.1016/ S0090-4295(00)01055-4

Ralla, B., Stephan, C., Meller, S., Dietrich, D., Kristiansen, G., and Jung, K. (2014). Nucleic acid-based biomarkers in body fluids of patients with urologic malignancies. Crit. Rev. Clin. Lab. Sci. 51 (4), 200-231. doi: 10.3109/10408363.2014.914888

Sanli, O., Dobruch, J., Knowles, M. A., Burger, M., Alemozaffar, M., Nielsen, M. E., et al. (2017). Bladder cancer. Nat. Rev. Dis. Primers 3, 17022. doi: 10.1038/ nrdp.2017.22

Sapre, N., Anderson, P. D., Costello, A. J., Hovens, C. M., and Corcoran, N. M. (2014). Gene-based urinary biomarkers for bladder cancer: an unfulfilled promise? Urol. Oncol. 32 (1), 48 e49-48 e17. doi: 10.1016/j.urolonc.2013.07.002 
Schrag, D., Hsieh, L. J., Rabbani, F., Bach, P. B., Herr, H., and Begg, C. B. (2003). Adherence to surveillance among patients with superficial bladder cancer. J. Natl. Cancer Inst. 95 (8), 588-597. doi: 10.1093/jnci/95.8.588

Serizawa, R. R., Ralfkiaer, U., Steven, K., Lam, G. W., Schmiedel, S., Schuz, J., et al. (2011). Integrated genetic and epigenetic analysis of bladder cancer reveals an additive diagnostic value of FGFR3 mutations and hypermethylation events. Int. J. Cancer 129 (1), 78-87. doi: 10.1002/ijc.25651

Sibley, K., Cuthbert-Heavens, D., and Knowles, M. A. (2001). Loss of heterozygosity at 4 p16.3 and mutation of FGFR3 in transitional cell carcinoma. Oncogene 20 (6), 686-691. doi: 10.1038/sj.onc. 1204110

Soloway, M. S., Briggman, V., Carpinito, G. A., Chodak, G. W., Church, P. A., Lamm, D. L., et al. (1996). Use of a new tumor marker, urinary NMP22, in the detection of occult or rapidly recurring transitional cell carcinoma of the urinary tract following surgical treatment. J. Urol. 156 (2 Pt 1), 363-367. doi: 10.1016/S0022-5347(01)65851-8

Springer, S. U., Chen, C. H., Rodriguez Pena, M. D. C., Li, L., Douville, C., Wang, Y., et al. (2018). Non-invasive detection of urothelial cancer through the analysis of driver gene mutations and aneuploidy. Elife 7. doi: 10.7554/eLife.32143

Tetu, B., Tiguert, R., Harel, F., and Fradet, Y. (2005). ImmunoCyt/uCyt+ improves the sensitivity of urine cytology in patients followed for urothelial carcinoma. Mod. Pathol. 18 (1), 83-89. doi: 10.1038/modpathol.3800262

Togneri, F. S., Ward, D. G., Foster, J. M., Devall, A. J., Wojtowicz, P., Alyas, S., et al. (2016). Genomic complexity of urothelial bladder cancer revealed in urinary cfDNA. Eur. J. Hum. Genet. 24 (8), 1167-1174. doi: 10.1038/ejhg.2015.281

Tomlinson, D. C., Baldo, O., Harnden, P., and Knowles, M. A. (2007). FGFR3 protein expression and its relationship to mutation status and prognostic variables in bladder cancer. J. Pathol. 213 (1), 91-98. doi: 10.1002/path.2207

Van der Heijden, A. G., and Alfred Witjes, J. (2009). Recurrence, progression, and follow-up in non-muscle-invasive bladder cancer. Eur. Urol. Suppl. 8 (7), 556562. doi: 10.1016/j.eursup.2009.06.010

van Kessel, K. E., Kompier, L. C., de Bekker-Grob, E. W., Zuiverloon, T. C., Vergouwe, Y., Zwarthoff, E. C., et al. (2013). FGFR3 mutation analysis in voided urine samples to decrease cystoscopies and cost in nonmuscle invasive bladder cancer surveillance: a comparison of 3 strategies. J. Urol. 189 (5), 1676-1681. doi: 10.1016/j.juro.2012.11.005

van Rhijn, B. W., Vis, A. N., van der Kwast, T. H., Kirkels, W. J., Radvanyi, F., Ooms, E. C., et al. (2003). Molecular grading of urothelial cell carcinoma with fibroblast growth factor receptor 3 and MIB-1 is superior to pathologic grade for the prediction of clinical outcome. J. Clin. Oncol. 21 (10), 1912-1921. doi: 10.1200/JCO.2003.05.073

van Rhijn, B. W., van der Kwast, T. H., Liu, L., Fleshner, N. E., Bostrom, P. J., Vis, A. N., et al. (2012). The FGFR3 mutation is related to favorable pT1 bladder cancer. J. Urol. 187 (1), 310-314. doi: 10.1016/j.juro.2011.09.008

Vinagre, J., Almeida, A., Populo, H., Batista, R., Lyra, J., Pinto, V., et al. (2013). Frequency of TERT promoter mutations in human cancers. Nat. Commun. 4, 2185. doi: $10.1038 /$ ncomms 3185

Vinagre, J., Pinto, V., Celestino, R., Reis, M., Populo, H., Boaventura, P., et al. (2014). Telomerase promoter mutations in cancer: an emerging molecular biomarker? Virchows Arch. 465 (2), 119-133. doi: 10.1007/s00428-014-1608-4

Wang, F., Li, X., Xie, X., Zhao, L., and Chen, W. (2008). UCA1, a non-proteincoding RNA up-regulated in bladder carcinoma and embryo, influencing cell growth and promoting invasion. FEBS Lett. 582 (13), 1919-1927. doi: 10.1016/j.febslet.2008.05.012

Wang, K., Liu, T., Ge, N., Liu, L., Yuan, X., Liu, J., et al. (2014). TERT promoter mutations are associated with distant metastases in upper tract urothelial carcinomas and serve as urinary biomarkers detected by a sensitive castPCR. Oncotarget 5 (23), 12428-12439. doi: 10.18632/oncotarget.2660

Wu, S., Huang, P., Li, C., Huang, Y., Li, X., Wang, Y., et al. (2014). Telomerase reverse transcriptase gene promoter mutations help discern the origin of urogenital tumors: a genomic and molecular study. Eur. Urol. 65 (2), 274-277. doi: 10.1016/j.eururo.2013.10.038

Yafi, F. A., Brimo, F., Steinberg, J., Aprikian, A. G., Tanguay, S., and Kassouf, W. (2015). Prospective analysis of sensitivity and specificity of urinary cytology and other urinary biomarkers for bladder cancer. Urol. Oncol. 33 (2), 66 e25-66 e31. doi: 10.1016/j.urolonc.2014.06.008

Yeung, C., Dinh, T., and Lee, J. (2014). The health economics of bladder cancer: an updated review of the published literature. Pharmacoeconomics 32 (11), 1093-1104. doi: 10.1007/s40273-014-0194-2

Ying, L., Chen, Q., Wang, Y., Zhou, Z., Huang, Y., and Qiu, F. (2012). Upregulated MALAT-1 contributes to bladder cancer cell migration by inducing epithelial-tomesenchymal transition. Mol. Biosyst. 8 (9), 2289-2294. doi: 0.1039/c2mb25070e

Ying, L., Huang, Y., Chen, H., Wang, Y., Xia, L., Chen, Y., et al. (2013). Downregulated MEG3 activates autophagy and increases cell proliferation in bladder cancer. Mol. Biosyst. 9 (3), 407-411. doi: 10.1039/C2MB25386K

Zuiverloon, T. C., van der Aa, M. N., van der Kwast, T. H., Steyerberg, E. W. Lingsma, H. F., Bangma, C. H., et al. (2010). Fibroblast growth factor receptor 3 mutation analysis on voided urine for surveillance of patients with low-grade non-muscle-invasive bladder cancer. Clin. Cancer Res. 16 (11), 3011-3018. doi: 10.1158/1078-0432.CCR-09-3013

Zwarthoff, E. C. (2008). Detection of tumors of the urinary tract in voided urine. Scand. J. Urol. Nephrol. Suppl (218), 147-153. doi: 10.1080/03008880802283953

Conflict of Interest: RB, JV, HP, and PS are the founders of U-Monitor Lda, owner of the Uromonitor product. This company has licensed technologies from Ipatimup that are related to the work described in this paper (International Patent PCT/PT2016/050007-Method, sequences, compositions and kit for detection of mutations in the $\mathrm{h}$ gene promoter).

The remaining authors declare that the research was conducted in the absence of any commercial or financial relationships that could be construed as a potential conflict of interest.

Copyright (C) 2019 Batista, Vinagre, Prazeres, Sampaio, Peralta, Conceição, Sismeiro, Leão, Gomes, Furriel, Oliveira, Torres, Eufrásio, Azinhais, Almeida, Gonzalez, Bidovanets, Ecke, Stinjs, Pascual, Abdelmalek, Villafruela, Beardo-Villar, Fidalgo, Öztürk, Gonzalez-Enguita, Monzo, Lopes, Álvarez-Maestro, Servan, De La Cruz, Perez, Máximo and Soares. This is an open-access article distributed under the terms of the Creative Commons Attribution License (CC BY). The use, distribution or reproduction in other forums is permitted, provided the original author(s) and the copyright owner(s) are credited and that the original publication in this journal is cited, in accordance with accepted academic practice. No use, distribution or reproduction is permitted which does not comply with these terms. 